\title{
The Labrador Sea Deep Convection Experiment
}

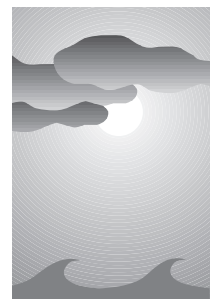

The Lab Sea Group*

\begin{abstract}
In the autumn of 1996 the field component of an experiment designed to observe water mass transformation began in the Labrador Sea. Intense observations of ocean convection were taken in the following two winters. The purpose of the experiment was, by a combination of meteorological and oceanographic field observations, laboratory studies, theory, and modeling, to improve understanding of the convective process in the ocean and its representation in models. The dataset that has been gathered far exceeds previous efforts to observe the convective process anywhere in the ocean, both in its scope and range of techniques deployed. Combined with a comprehensive set of meteorological and air-sea flux measurements, it is giving unprecedented insights into the dynamics and thermodynamics of a closely coupled, semienclosed system known to have direct influence on the processes that control global climate.
\end{abstract}

\section{Introduction}

\section{a. Meteorology and oceanography of the Labrador Sea}

The northwest corner of the Atlantic Ocean (the Labrador Sea sketched in Fig. 1) is a region of powerful physical forces, extremes of wind and cold, incur-

*The Lab Sea Group:

J. Marshall, Massachusetts Institute of Technology, Cambridge, Massachusetts.

F. Dobson, Bedford Institute of Oceanography, Dartmouth, Nova Scotia, Canada.

K. Moore, University of Toronto, Toronto, Canada.

P. Rhines, University of Washington, Seattle, Washington.

M. Visbeck, Lamont-Doherty Earth Observatory, Palisades, New York.

E. d'Asaro, Department of Meteorology, University of Washington, Seattle, Washington.

K. Bumke, Department of Meteorology, Institut für Meereskunde, University of Kiel, Kiel, Germany.

S. Chang, Naval Research Laboratory, Monterey, California.

R. Davis, Scripps Institution of Oceanography, San Diego, California.

K. Fischer, Environmental Research Institute of Michigan, Ann Arbor, Michigan.

R. Garwood, Naval Postgraduate School, Monterey, California.

P. Guest, Naval Postgraduate School, Monterey, California.

R. Harcourt, Naval Postgraduate School, Monterey, California.

C. Herbaut, Massachusetts Institute of Technology, Cambridge, Massachusetts. sions of icebergs and sea ice, great contrasts in buoyancy of air and seawater, and a region of great biological activity. Intense air-sea interaction occurs here with strong upward heat flux at the sea surface. The proximity of the region to the principal North Atlantic storm track of the atmosphere results in a strong modulation of air-sea interaction by passing extratropical cyclones.

T. Holt, Naval Research Laboratory, Monterey, California.

J. Lazier, Bedford Institute of Oceanography, Dartmouth, Nova Scotia, Canada.

S. Legg, Woods Hole Oceanographic Institution, Woods Hole, Massachusetts.

J. McWilliams, University of California, Los Angeles, Los Angeles, California.

R. Pickart, Woods Hole Oceanographic Institution, Woods Hole, Massachusetts.

M. Prater, University of Rhode Island, Kingston, Rhode Island. I. Renfrew, University of Toronto, Toronto, Canada.

F. Schott, Department of Meteorology, Institut für Meereskunde, University of Kiel, Kiel, Germany.

U. Send, Department of Meteorology, Institut für Meereskunde, University of Kiel, Kiel, Germany.

W. Smethie, Lamont-Doherty Earth Observatory, Palisades, New York.

Corresponding author address: Dr. John Marshall, Bldg. 54-1256, Department of Earth, Atmosphere, and Planetary Studies, Massachusetts Institute of Technology, Cambridge, MA 02139.

E-mail: marshall@gulf.mit.edu

In final form 24 July 1998.

(C)1998 American Meteorological Society 


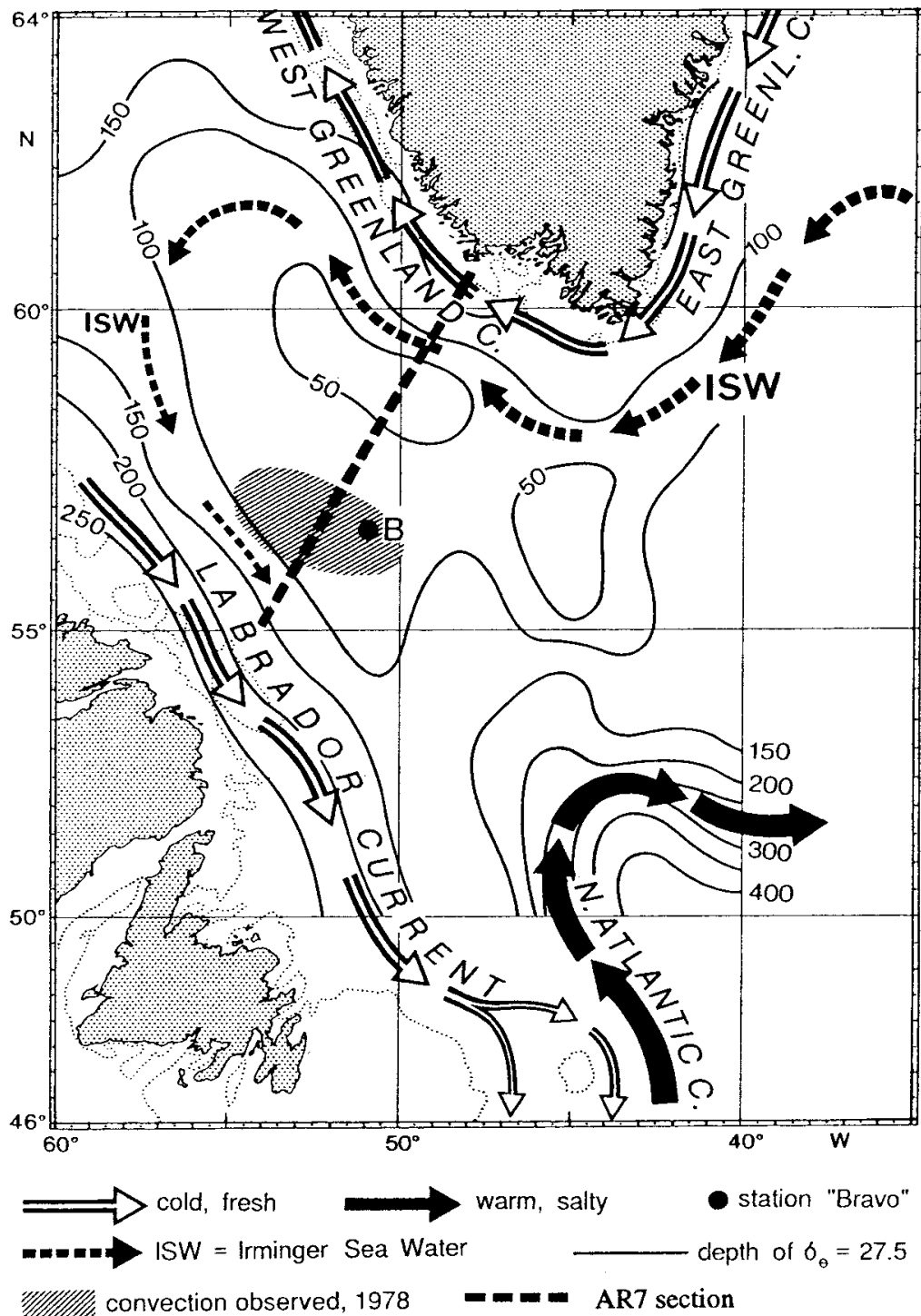

FIG. 1. Schematic showing the cyclonic circulation and preconditioning of the Labrador Sea. The typical depth of the $\sigma=27.6$ isopycnal in the early winter is contoured in meters. The warm circulation branches of the North Atlantic Current and Irminger sea water (ISW) and the near-surface, cold, and fresh East/West Greenland and Labrador Currents are also indicated. (From Marshall and Shott 1998.) ocean to sink. But because the fluid is stiffened by the earth's rotation, sinking of the cooled water compresses "Taylor columns," generating strong horizontal circulation. The heat lost from the ocean is taken up by the atmosphere, which also responds in a convective manner. But because the timescale of response in the atmosphere is so much shorter, here rotation is not an important constraint on the motion. As a result, the convection that occurs over the Labrador Sea has a very different manifestation from that which occurs in it, often being organized in a quasi-linear manner that results in roll clouds that are a ubiquitous feature in satellite images of the region (e.g., see Fig. 2). However, atmospheric convection is tied to the topography of the basin and thus affects the pattern of surface buoyancy fluxes; it is very much part of the coupled problem.

The important convection, climate, and circulation of the Labrador Sea, to be described further below, encouraged us to follow the historic lead of earlier Canadian initiatives and develop a multicomponent program of observations and modeling. Prompted by simulations of rotating convection on the computer (e.g., Jones and Marshall 1993) and in the laboratory (e.g., Maxworthy and Narimousa 1994) and by the establishment of a National Oceanic and Atmospheric Association (NOAA)-funded time series mooring in the central Labrador Sea, the U.S. Office of Naval Research formed the Accelerated Research Initiative on Oceanic Deep Convection.

The deep convection experiment,

The response of the Labrador Sea involves a fundamental fluid dynamical process: buoyancy-driven convection on a rapidly rotating planet. Heat loss from the ocean is induced by cyclonic atmospheric circulation over the North Atlantic in winter, which advects cold, dry arctic air over the relatively warm $\left(\sim 2^{\circ} \mathrm{C}\right)$ waters of the Labrador Sea. Peak heat losses in winter can reach many hundreds of watts per square meter (G. Moore et al. 1998, manuscript submitted to J. Climate, hereafter MAH; I. Renfrew and G. Moore 1998, manuscript submitted to Mon. Wea. Rev.) and the resultant buoyancy loss causes the surface waters of the whose field program began in the autumn of 1996, has as its primary focus the oceanic convective process and its interaction with geostrophic and basin-scale eddies and circulation. But its proximate goals have grown to be major efforts in themselves: the investigation of the atmospheric, synoptic, and mesoscale dynamics that result in intense air-sea interaction in the region; the coupled dynamics of the deep convection process in the atmosphere and ocean; the communication of newly convected waters of the Labrador Sea with the World Ocean; and the relation between convection and decadal climate variability. 
The experiment took place, quite fortuitously, in the larger context of the Frontal and Atlantic Storm-track Experiment (FASTEX) and the validation program for the National Aeronautics and Space Administration (NASA) scatterometer on the Advanced Earth Observing Satellite. The FASTEX goals were to investigate, with a new range of forecast models, the development and evolution of lowpressure systems over the North Atlantic Ocean (see Joly et al. 1997). We also benefited by the large-scale oceanographic description provided by international efforts organized by the World Ocean Circulation Experiment (WOCE) in the Atlantic Ocean. The context provided by these related experiments will provide a much clearer and more complete picture of the synoptic meteorology and ambient oceanographic conditions that occurred in the Labrador Sea and its environs.

Advanced and newly conceived technologies abound in the Labrador Sea experiment;

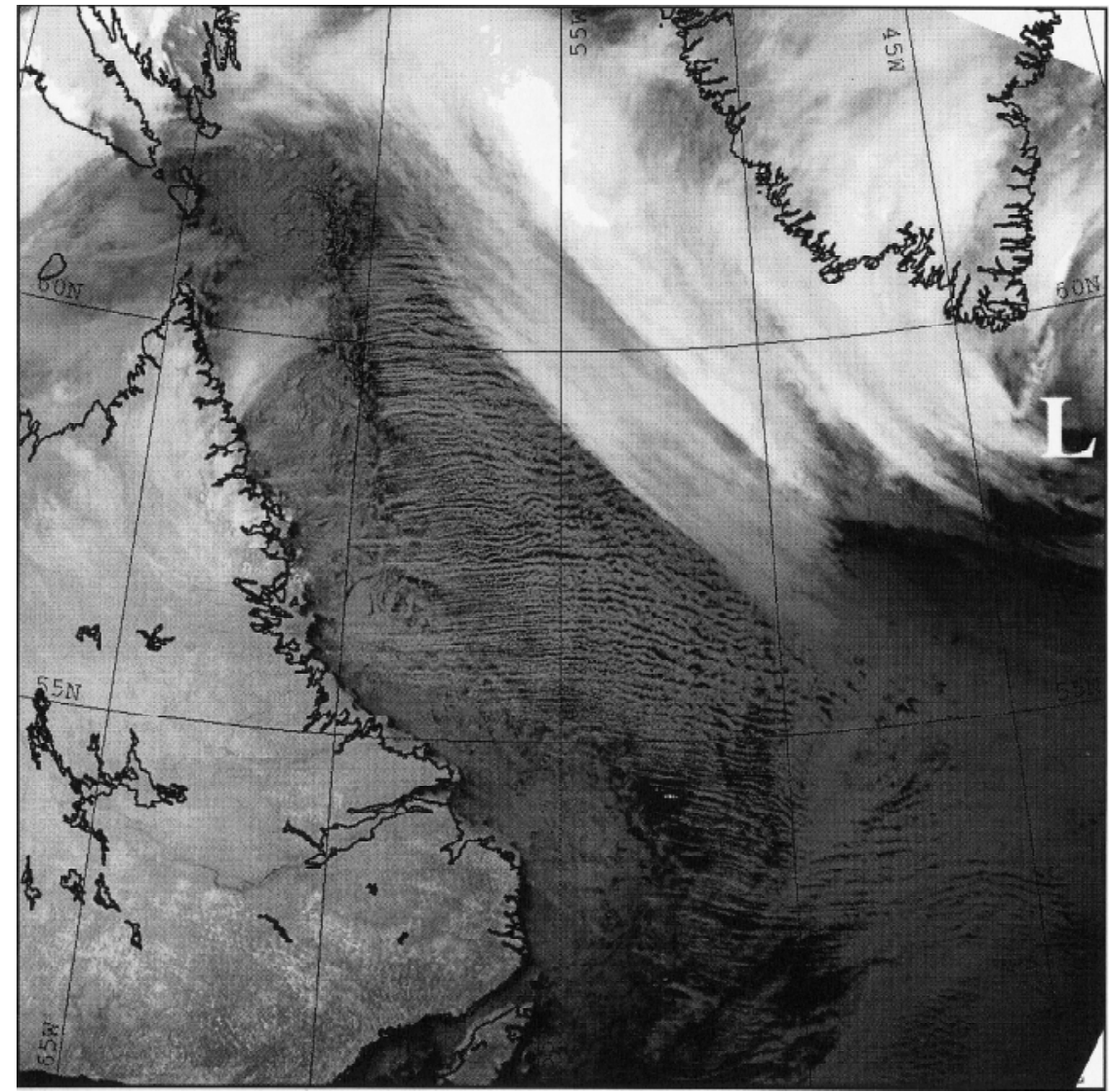

FIG. 2. Infrared advanced very high resolution radiometer image from the NOAA-14 polar orbiter at 1141 UTC on 7 February 1997 showing an extratropical cyclone over the North Atlantic. The location of the low pressure center is indicated by the L. The bright and therefore high clouds to the north of the low pressure center are associated with the system's warm sector. The less bright and therefore shallow clouds to the east of the low, organized into quasi-two-dimensional bands, are associated with the northwesterly flow that results in the advection of cold and dry polar air over the Labrador Sea. beyond classic hydrographic

sections and moorings measuring velocity, salinity, and temperature, we deployed drifting and profiling floats; three-dimensional nearly Lagrangian drifters that can follow the convective process vertically as well as horizontally; acoustic tomography and vertical echo sounding aimed at long-baseline temperature, salinity, and currents; newly designed conductivitytemperature-depth profiler (CTD) moorings, and moored and lowered acoustic Doppler current profilers; shipboard air-sea flux instrumentation; wave radar systems; airborne and satellite passive microwave and scatterometer systems; and synthetic aperture radars. In the second season of field work, 1997-98, autonomous underwater vehicles were also deployed to map fine structure in the boundary layer. The datasets that have been and are being gathered far exceed previous efforts to observe the convective process anywhere in the ocean, both in the scope and range of techniques deployed. We are now in a position to test new theoretical ideas, the fidelity of ocean general circulation models, parameterizations of convective mixing, and to explore new and exciting scientific territory.

Here we give an overview of the important scientific issues that are being addressed by the experiment and provide a preliminary description of results from the field work. The paper is set out as follows. After a statement of the major aims of the experiment, we discuss the circulation and climatological context in which it is being carried out and some of the theoretical and modeling issues that motivate it in section 2. The planning of the multifaceted experiment is discussed in section 3 and some of our preliminary findings in section 4 . Finally, conclusions and the future outlook are presented in section 5 . 


\section{b. Aims of the experiment}

Many of the details of the water mass transformation process in the ocean remain largely unknown because they are difficult to observe and model. The overarching goal of the Labrador Sea Convection Experiment (LSCE) is then to improve our understanding of the convective process in the ocean, and hence the fidelity of its parametric representation in largescale ocean models, through a combination of meteorological and oceanographic field observations, laboratory studies, theory, and modeling.

The water mass transformation process in the ocean is inherently complicated, involving air-sea interaction and the interplay of a hierarchy of oceanic scales: convective plumes (on scales of order $1 \mathrm{~km}$ ) that act to homogenize properties to form a "mixed patch," eddies that orchestrate "lateral exchange" between the mixed patch and the ambient fluid through advective processes (on a scale of a few tens of kilometers), and the large-scale circulation itself (over hundreds of kilometers) involving the ocean gyre and boundary currents. The scales of the key phenomenon are represented schematically in Fig. 3.

Our modeling and observational strategies were designed to address each of the scales and its interaction in the context of the prevailing meteorological forcing that drives the whole process in the depths of winter. The key oceanographic and meteorological objectives are outlined below.

\section{1) OCEAN}

The objectives at each of the oceanographic scales are as follows.

- Plume scale (100 m-1 km): Determine the characteristic scales, properties, and integral fluxes of a population of convective plumes and how they depend on the atmospheric forcing and their local environment.

- Eddy scale $(5 \mathrm{~km}-100 \mathrm{~km})$ : Understand how the convective process is related to and organized by its large-scale environment and the relative importance of balanced (geostrophic) versus unbalanced (nonhydrostatic) processes in the flux of heat and salt both laterally and vertically.

- Gyre scale (50-1000 km): Determine the largescale factors that control the volume and temperature/salinity (T/S) properties of the convectively created water masses and how they are subsequently accommodated into the general circulation of the ocean; describe the mean and seasonal varia-

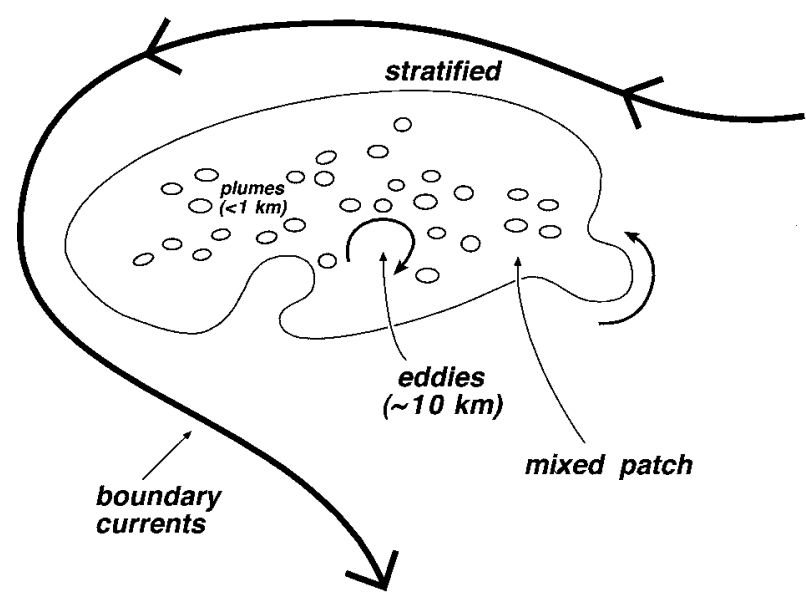

FIG. 3. Scales of phenomena involved in deep convection: the mixed patch on the preconditioned scale created by convective plumes and geostrophic eddies that orchestrate the exchange of fluid and properties between the mixed patch and the stratified fluid associated with the peripheral boundary current.

tion in the circulation of the Labrador sea.

\section{2) Atmosphere}

The aims of the meteorological component of the experiment are to

- understand the physics of the atmospheric processes in the Labrador Sea that force oceanic mixing and deep convection;

- collect a set of high quality in situ surface fluxes of heat, fresh water, radiation, and momentum in conditions representative of those in which deep convection occurs;

- use the in situ measurements to "test" remotely sensed products; and

- use the in situ measurements to assess the ability of atmospheric numerical models to correctly represent the air-sea interaction that occurs in the region and, where needed, improve the boundary layer parameterization in these models so as to better represent the interaction.

\section{Background}

\section{a. The Labrador Sea}

The weak density stratification of the Labrador Sea is broken down each wintertime, recently to depths greater than $2000 \mathrm{~m}$, making it one of the most extreme ocean convection sites in the World Ocean. A lensshaped water mass (Labrador sea water, or LSW) of 
dimension $500 \mathrm{~km} \times 700 \mathrm{~km} \times 2 \mathrm{~km}$ deep has developed in response to this wintertime air-sea heat flux (Fig. 4). It is weakly stratified, with a temperature near $2.8^{\circ} \mathrm{C}$, a salinity of $34.83 \mathrm{ppt}$, and a potential density of $27.78 \mathrm{~kg} \mathrm{~m}^{-3}$. Deep convective cooling to the atmosphere competes with the buoyant, low-salinity nearsurface waters nearby and with the warmth of the subtropical waters just beneath the surface. The net effect on the oceanic general circulation is to transport salt and heat poleward in the surface layers and lowsalinity, cooled waters southward to the rest of the World Ocean at depths between 1 and $2 \mathrm{~km}$, producing fresh new deep water on a quasi-continuous basis, with all the climate implications of such a production. The Labrador Sea is also an important component of the "thermohaline circulation," the global meridional-overturning circulation that is responsible for roughly half of the poleward heat transport demanded by the atmosphere-ocean system.

Figure 5 shows the average mean sea level pressure, 10-m wind, and total heat flux fields for all winter months during the period from 1968 to 1997, as determined by the National Centers for Environmental Prediction-National Center for Atmospheric Research (NCEP-NCAR) Reanalysis Project (Kalnay et al. 1996). Note in this context a winter is defined as the months of December, January, February, and March. One can see that in winter the North Atlantic is under the influence of the Icelandic low and the Azores high. Thus one would expect cyclonic flow over the North Atlantic associated with the movement of synoptic-scale weather systems along a track from the eastern seaboard of North America to Iceland. This "mean" cyclonic circulation over the North Atlantic results in the advection of cold and dry arctic air over the relatively warm waters $\left(\sim 2^{\circ} \mathrm{C}\right)$ of the Labrador Sea, resulting in a large transfer of heat from the ocean to the atmosphere as shown in Fig. 5. In the center of the Labrador Sea, the average winter heat loss exceeds $300 \mathrm{~W} \mathrm{~m}^{-2}$, a value that is of the same order of magnitude as that which occurs in the temperate Sargasso Sea to the east of the Gulf Stream. Although averaging tends to blur spatial gradients, the highest heat loss in the Labrador Sea occurs in an elliptical region some $150 \mathrm{~km}$ wide situated along the Labrador coast just off the

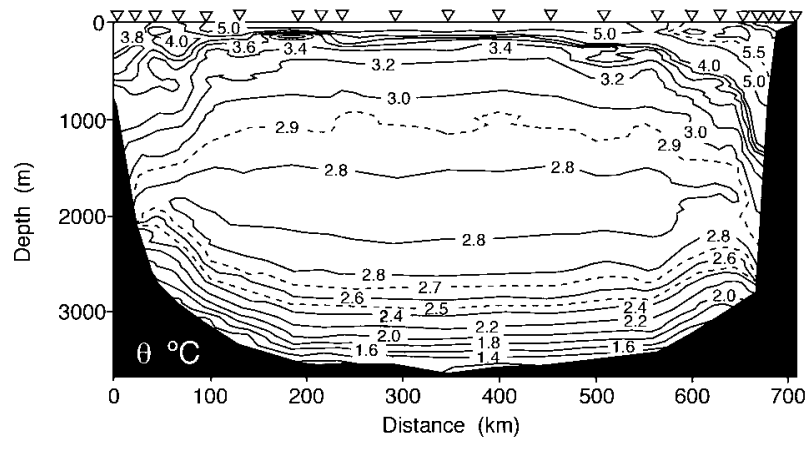

FIG. 4. Autumn hydrographic section of potential temperature (October 1996) along AR7 (marked in Fig. 1) showing the lensshaped bolus of Labrador Sea water extending down to about $2 \mathrm{~km}$, formed by convection in previous winters (courtesy of A. Clarke and J. Lazier).

sea-ice edge where peak values can exceed $1000 \mathrm{~W} \mathrm{~m}^{-2}$.

The surface waters of the Labrador Sea are sufficiently warm, except near the sea-ice margin, that their contraction under cooling can cause convective overturning. The delicate balance of the cold and fresh water from continental runoff and sea-ice melt, and the inflow of the warm and salty water of the Irminger Current (see Fig. 1) maintains the temperature and salinity of the surface waters at elevated values.

In addition to the large uncertainty that exists with regard to the spatial and temporal variability in the airsea flux in the region, the equally important freshwater cycle has received much less attention. The precipitation-induced supply of buoyancy to the surface waters of the Labrador Sea can have a direct im-

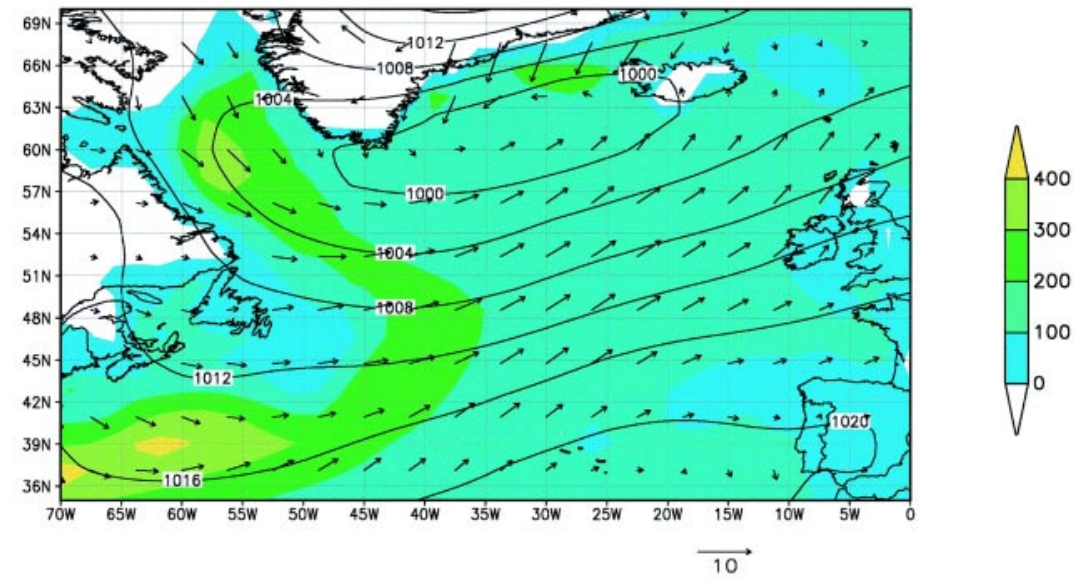

FIG. 5. Average mean sea level pressure (contour, mb), 10-m wind (vector, $\mathrm{m} \mathrm{s}^{-1}$ ), and total heat flux (color scale, $\mathrm{W} \mathrm{m}^{-2}$ ) fields from the NCEP-NCAR Reanalysis over all winter months (December, January, February, March) during the period 1968-97. 
pact on the convective process in the ocean (MAH). Supply through river runoff, freshwater release in ice melt as well as advection by ocean currents are all important in the buoyancy budget. Direct measurements show significant ( $>1$ Sverdrup) inflow from the Arctic through the Davis Strait, as well as input via the East Greenland Current. The freshwater runoff from Canada is also very great, evident for example in the high tritium concentration of surface waters (tritium that is locked up in continental ground water and ice is relatively undiluted, compared with ocean-borne tritium).

\section{THE CONVECTIVE PROCESS}

Observations suggest that there are certain recurring features and conditions that predispose a region to deep-reaching convection and that are common to all known sites of deep convection-the Mediterranean, Greenland, and Labrador seas (e.g., see Marshall and Schott 1998). First, there must be strong atmospheric forcing due to thermal and/or haline surface fluxes. Thus open ocean regions adjacent to boundaries are favored, where cold and dry winds from land or ice surfaces blow over water inducing large sensible and latent heat and moisture fluxes. Second, the stratification beneath the surface mixed layer must be weak, made weak perhaps by previous convection. And third, the weakly stratified underlying waters must be brought up toward the surface so that they can be readily and directly exposed to intense surface forcing. This latter condition is favored by cyclonic circulation associated with density surfaces that "dome up" to the surface. All these conditions are readily satisfied in the Labrador Sea (see Fig. 1).

Since the classic MEDOC experiment in the Mediterranean (MEDOC Group 1969) three phases of ocean convection have been identified (sketched schematically in Fig. 6) and provide a useful context to consider the convective process in the Labrador Sea (see Clarke and Gascard 1983): "preconditioning" on the large scale (of order $100 \mathrm{~km}$ ), "deep convection" occurring in localized, intense plumes (on scales of order $1 \mathrm{~km}$ ), and lateral exchange between the convection site and its surroundings. The last two phases are not necessarily sequential and often occur concurrently.

During preconditioning (Fig. 6, panel I), the gyrescale cyclonic circulation and buoyancy forcing typical of the convection site predispose it to overturn. Subsequent cooling events may then initiate deep convection in which a substantial part of the fluid column may overturn in numerous plumes (Fig. 6, panel II) that distribute the dense surface water in the vertical. The plumes are thought to have a horizontal scale of the order of their lateral scale, $\sim 1 \mathrm{~km}$, with vertical velocities of up to $10 \mathrm{~cm} \mathrm{~s}^{-1}$. They mix properties over the preconditioned site, forming a homogeneous deep mixed patch ranging in scale from several tens to perhaps many hundreds of kilometers in diameter. With the cessation of strong forcing, the predominantly vertical heat transfer due to convection gives way to horizontal transfer associated with eddying on geostrophic scales. The mixed fluid disperses under the influence of gravity and rotation, spreading out at its neutrally buoyant level, leading, on a timescale of weeks, to the disintegration of the mixed patch and reoccupation of the convection site by the stratified fluid of the periphery (Fig. 6, panel III).

The above conceptual idealization provides a useful ordering of our ideas when thinking about the convective process in the Labrador Sea, albeit modified by geographical detail and particularly the proximity of boundaries and boundary currents (see Fig. 3), which can provide an effective conduit for convected fluid away from its formation region.

\section{b. The climatic context}

1) The North Atlantic Oscillation

The northwest Atlantic is an important center of action for global climate, in part because of the huge upward heat flux at the sea surface in winter and in part due to the sympathetic arrangement of orography both locally (the Greenland Plateau) and globally (in particular, the Rocky Mountains). The North Atlantic Oscillation (NAO) measures the strength of the cyclonic circulation and climate variability over the region (van Loon and Rogers 1978; Rogers 1990; Hurrell 1995). The positive phase of the NAO occurs when the Icelandic low is anomalously deep and the Azores high is anomalously shallow. When the NAO is high there is greater cyclonic activity and hence a stronger mean cyclonic flow over the North Atlantic with an enhanced circulation of cold air out of the Canadian Arctic. The opposite occurs in the negative phase. Generally, then, one might expect higher oceanic heat loss from the Labrador Sea during the positive phase of the oscillation and lower heat loss during the negative phase.

\section{2) VARIABILITY IN DEEP CONVECTION}

Orchestration of Labrador Sea and Greenland Sea deep convection by the NAO is described by Dickson et al. (1996). The ocean has an immediate, shallow response to atmospheric variability but also has a 
longer response through the advection of shallow salinity anomalies (together with a response that can extend out to millennia in the deep ocean).

Observations of SST in hostile regions like the wintertime Labrador Sea are very sparse and are difficult to interpret because of the large $\left(\sim 6^{\circ} \mathrm{C}\right)$ annual cycle of SST. At about 100-m depth, however, the annual cycle is down to $\sim 1.5^{\circ} \mathrm{C}$ and decadal variability stands out (e.g., Levitus et al. 1994; Reverdin et al. 1997). At $1000 \mathrm{~m}$ the annual cycle is $0.2^{\circ} \mathrm{C}$, decadal variability is muted, and 10-100-yr variations dominate. The great volume of LSW makes it a useful stable reservoir for climate analysis. Over the past $100 \mathrm{yr}$, LSW has moved in a great counterclockwise loop in the potential-temperature/salinity diagram (Fig. 7). In the past decade or so the system has returned to a high 70-yr extreme NAO index, wonderfully deep convection (to a depth of $2200 \mathrm{~m}$ in 1992), and a Labrador Sea resembling that in the first few decades of the century. Meanwhile, as suggested by the seesaw between the Greenland high and Icelandic low, convection on the other side of Greenland, in the Greenland Sea, has been weak since the early 1980 s.

\section{c. Theory and modeling}

Laboratory and numerical studies of oceanic convection have been central to the planning of the field experiment and, particularly when used in concert with and scaled for comparison with the observations, have led to advances in our understanding of the general problem of convection in a rotating stratified fluid. Marshall and Schott (1998) review the key ideas and contributions in the context of the observations, models, and theory.

Two aspects make ocean convection interesting from a fundamental point of view. First, the timescales of the convective process in the ocean are sufficiently long that it may be modified by the earth's rotation. Second, the convective and geostrophic scales are not very disparate in the ocean and so the water mass transformation process involves a fascinating interplay between convection and baroclinic instability (the interaction between phases II and III in Fig. 6).
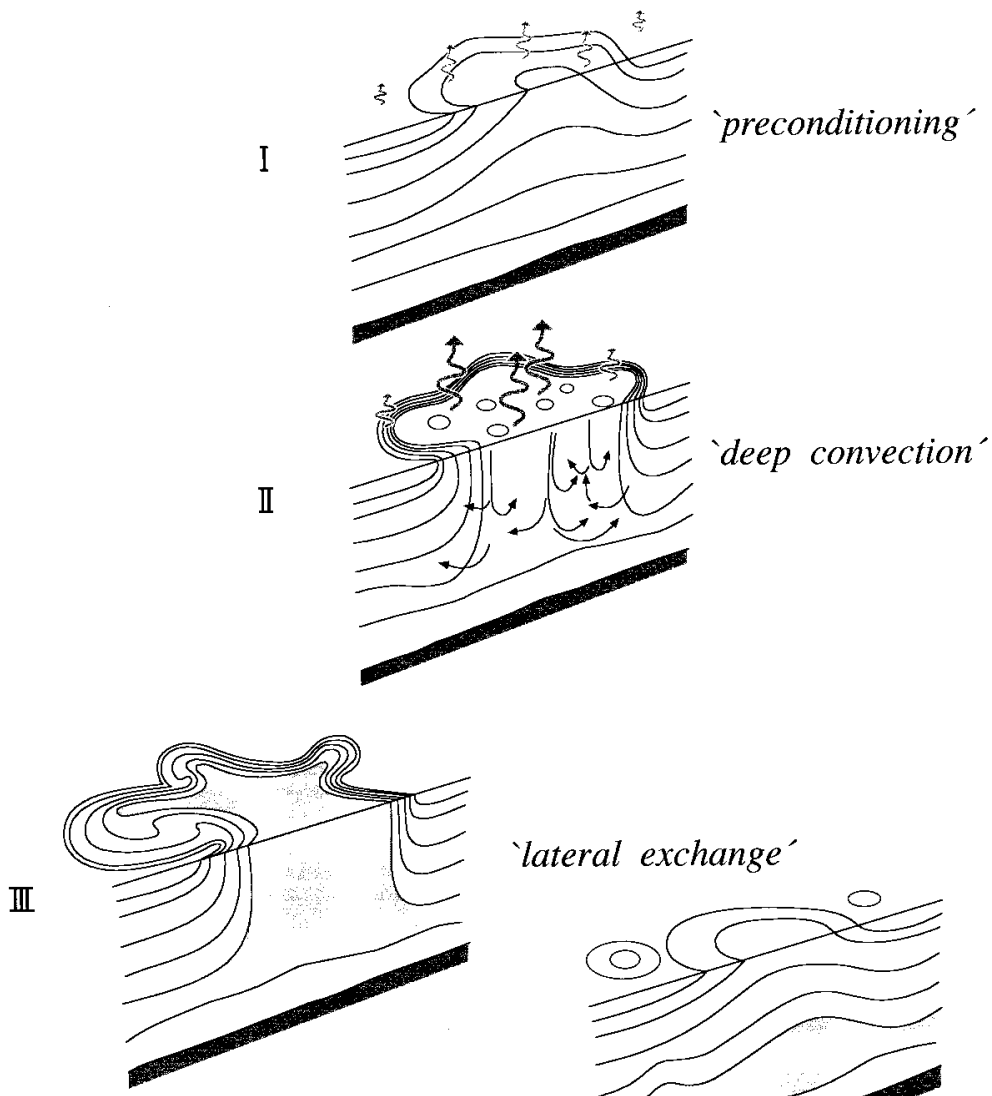

'lateral exchange'

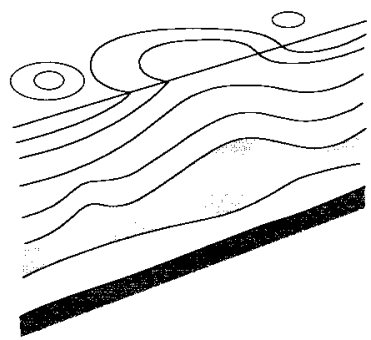

FIG. 6. A schematic diagram of the three phases of open-ocean deep convection: (I) preconditioning, (II) deep convection, and (III) lateral exchange and rent runs around the periphery. Fluid overturned and mixed by convection is shaded. (From Marshall and Schott 1998.)

This lack of a scale separation in the ocean should be contrasted with the atmosphere (e.g., see Fig. 2) where the convective scale (the "rolls" clearly evident in IR image) have a much smaller scale than that of the synoptic system in which they are embedded. This difference in the parameter range of atmospheric and oceanographic convection can be usefully expressed in terms of the size of a "natural Rossby number" that is small in the ocean but large in the atmosphere (see Jones and Marshall 1993; Maxworthy and Narimousa 1994). Moreover, in the ocean large horizontal buoyancy gradients on the edge of the convection patch support strong horizontal currents in thermal-wind balance with them-the "rim current" (see Fig. 3). If the patch has a lateral scale greater than the radius of deformation, then instability theory tells us that it must 


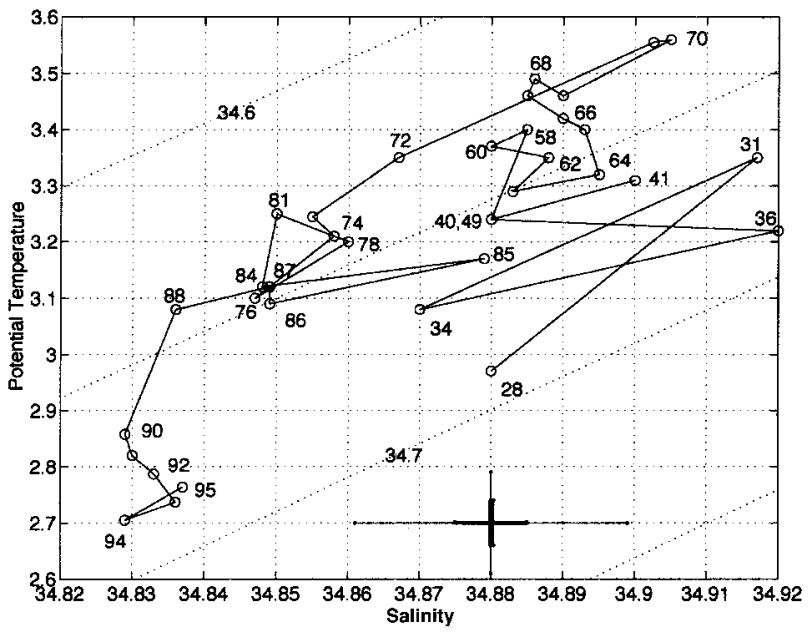

FIG. 7. Salinity (ppt) and potential temperature properties of Labrador Sea water from 1928 to 1995 (years marked). The water mass has moved around a counterclockwise path in this oceanographic phase space (P. Rhines, personal communication). The tilted dotted lines are isopleths of constant potential density $\left(\mathrm{kg} \mathrm{m}^{-3}\right)$, referred to $2 \mathrm{~km}$.

break up into deformation-radius-scale fragments. These edge effects play a dominant role in the dynamics and thermodynamics of the mixed patch, orchestrating the exchange of fluid and buoyancy to and from it (e.g., see Legg and Marshall 1993; Visbeck et al. 1996). Many of the issues can be beautifully illustrated in a simple laboratory experiment in which a disc of colored ice is gently floated on the surface of a rotating tank of water. The ice melts, drawing its latent heat of fusion from the water, thus inducing rotationally modified plumes that penetrate downward, mixing the water up from below. If the dish is rotating rapidly enough, the body of convectively modified water breaks up into eddies-conical structures that parcel up the convected fluid and carry it away to the periphery.

One of the central goals of the Labrador Sea project is to learn how to parametrically represent convection in limited-area and large-scale ocean models. Although hydrostatic adjustment remains the primary method of representing deep convection in ocean general circulation models, nonhydrostatic simulation of unsteady deep convection by Jones and Marshall (1993) has demonstrated the need to include vertical acceleration by buoyancy in the momentum budget on scales of kilometers and smaller. The budget of turbulent kinetic energy in deep convection, previously viewed simply as "turbulence," is now known to have interesting new physics that had never before been considered in mixed layer models: planetary rotation can influence the evolution of the mixing layer in the ocean; nonhydrostatic and $2 \Omega \cos$ (lat) terms can also play an important role, as can "thermobaric" effects (the increase in the thermal expansion coefficient with pressure; see Garwood 1991; Garwood et al. 1994).

A hierarchy of different models and resolutions has been used to study the interplay of scales sketched in Fig. 3 and the role of hitherto-neglected dynamics and physics. Studies focusing on the plume scale are typically carried out over domains only a few kilometers wide and are capable of resolving the full nonhydrostatic turbulent plume dynamics, as in Fig. 8. The subplume scales may either be explicitly resolved at Reynolds numbers somewhat less than the ocean (Julien et al. 1996) or accounted for by subgrid-scale turbulence models [as in the large-eddy simulations (LES) of Harcourt et al. (1997); Fig. 8]. Investigation of the interaction between the geostrophic scale and the plume scale requires resolution down to the plume scale but over domains several tens of kilometers

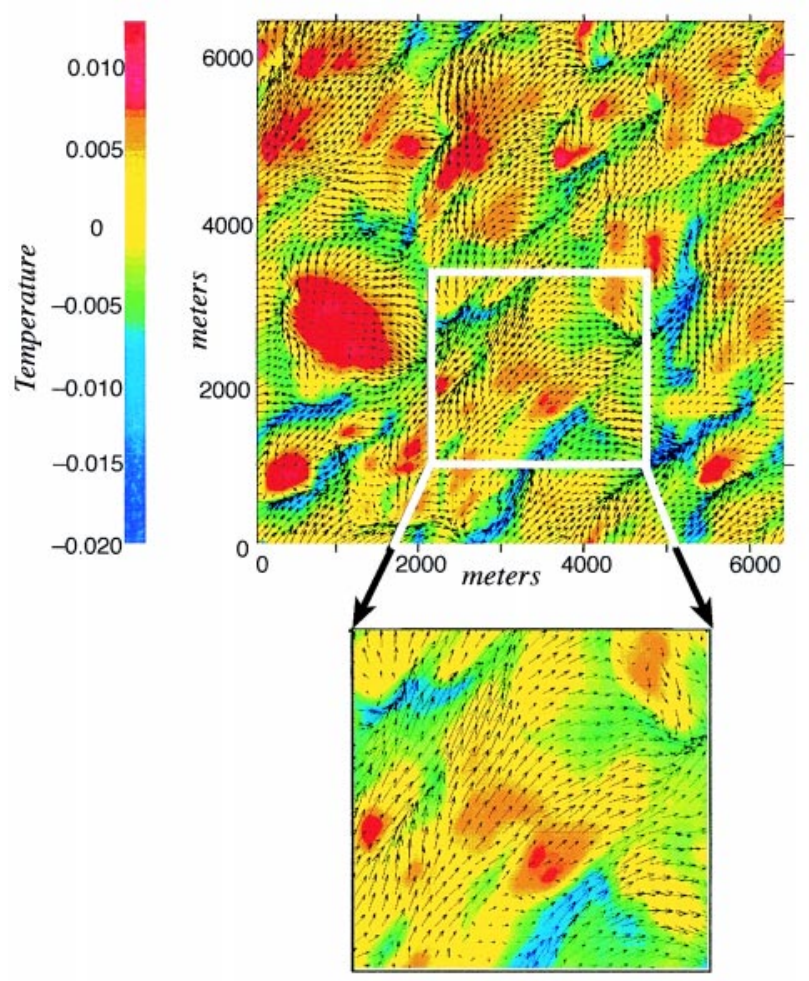

FIG. 8. Snapshot of surface $T(\mathrm{~K}), u$, and $v$ fields, in LES high-resolution simulation of ocean convection induced by a $400 \mathrm{~W} \mathrm{~m}^{-2}$ heat loss and $20 \mathrm{~m} \mathrm{~s}^{-1}$ winds applied at the surface. Currents reach speeds of a few tens of centimeters per second. The domain is $6 \mathrm{~km}$ by $6 \mathrm{~km}$ in the horizontal and $2 \mathrm{~km}$ deep. (See Harcourt et al. 1997.) 
across (Jones and Marshall 1993; Legg et al. 1997). Investigations of larger-scale dynamics, including the interaction between the basin-scale circulation and the water mass formation require parameterization of convection to account for turbulent transfer by unresolved plumes. Comparison of the results between these different model formulations at the overlapping scales and in the context of field data allows the validity of assumptions and approximations to be tested.

In addition to improving our understanding of the physical processes, modeling studies also help us to evaluate and interpret the response of different measurement systems to the turbulence, plumes, and geostrophic eddies. Simulations of Lagrangian and isobaric drifters, and comparison of their measurement records with Eulerian measurements of a field of convective turbulence (Harcourt et al. 1997), suggest that each of these three types of measurement systems has a particular advantage and that a mixture of all three is useful. Indeed, as described in section 3 , such a mix of observing strategies is being employed in the experiment. Other applications of modeling to the interpretation of observations include the simulation of synthetic aperture radar images of the surface fields associated with convection (Fischer et al. 1998).

\section{Planning the field experiment}

\section{a. Elements of the observational strategy}

\section{1) OCEAN}

The measurement of deep oceanic convection presents a formidable challenge due to the wide range of space and timescales involved and the intermittency of the process in space and time. The experimen- tal challenge was to measure both the large and small spatial scales over both short and long timescales in a remote location under very adverse conditions. A variety of experimental techniques was used (see Table 1 and Fig. 9). Measurements were carried out over a 2-yr period (summer 1996-summer 1998) in order to resolve the seasonal cycle and observe the convective process twice. The field work for the Convection Accelerated Research Initiative was embedded within an
TABLE 1. Elements of the oceanographic observational program.

\begin{tabular}{lll}
\hline \hline Hydrography & & \\
\hline \multicolumn{1}{c}{ Period } & \multicolumn{1}{c}{ Variables } & \multicolumn{1}{c}{ PI/Lab } \\
\hline Aug 1996 & T/S, O, N & F. Schott, IfM Kiel, Germany \\
Oct-Nov 1996 & T/S, O, N & A. Clarke, BIO, Canada \\
Feb-Mar 1997 & T/S, O, N CFC & R. Pickart, WHOI, US \\
May-Jun 1997 & T/S, O, N & J. Lazier, BIO, Canada \\
Aug 1997 & T/S, O, N & F. Schott, IfM Kiel, Germany
\end{tabular}

\section{Moorings}

\begin{tabular}{lll}
\multicolumn{1}{c}{ Instrument } & \multicolumn{1}{c}{ Variables } & \multicolumn{1}{c}{ PI/Lab } \\
\hline WOTAN & rainfall & D. Farmer, IOS, Canada \\
Seacat/Aanderaa & $u, v, w$ & P. Rhines, UW, USA; \\
& & J. Lazier, BIO, Canada \\
Seacat/Aanderaa/ADCP & $u, v, w$ & F. Schott, IfM Kiel, Germany \\
Tomography & $T$, vel & U. Send, IfM Kiel, Germany \\
Sound sources & Rafos tracking & M. Prater, URI
\end{tabular}

Floats and drifters

\begin{tabular}{lll}
\hline \multicolumn{1}{c}{ Instrument } & Variables & \multicolumn{1}{c}{ PI/Lab } \\
\hline 3D Lagrangian float & $u, v, w, T$ & E. D'Asaro, UW \\
PALACE/VCM & $\mathrm{T} / \mathrm{S}, u, v, w$ & R. Davis, SIO \\
Profiling RAFOS & $T, u, v, w$ & M. Prater, URI \\
PALACE/VCM & $\mathrm{T} / \mathrm{S}, u, v, w$ & B. Owens, WHOI \\
PALACE & $T, u, v$ & F. Schott, IfM Kiel, Germany \\
Surface drifter & Ts, pa, $u, v$ & P. Niiler, SIO \\
PALACE & $\mathrm{T} / \mathrm{S}, u, v$ & R. Schmidt, WHOI \\
\hline
\end{tabular}

Notes:

$\mathrm{T} / \mathrm{S}=$ temperature/salinty $; \mathrm{O}=$ oxygen; $\mathrm{N}$ = nutrients; $\mathrm{CFC}=$ chloroflourocarbons; $\mathrm{Ts}=$ surface temperature; $\mathrm{pa}=$ atmospheric pressure $;(\mathrm{u}, \mathrm{v})=$ horizontal velocity; $\mathrm{w}=$ vertical velocity.

$\mathrm{BIO}=$ Bedford Institute of Oceanography; IfM Kiel = Dept. of Meteorology, Institut für Meereskunde; IOS = Institute of Ocean Sciences; SIO = Scripps Institute of Oceanography; URI = University of Rhode Island; UW = Dept. of Meteorology, University of Washington; WHOI = Woods Hole Oceanographic Institution. 


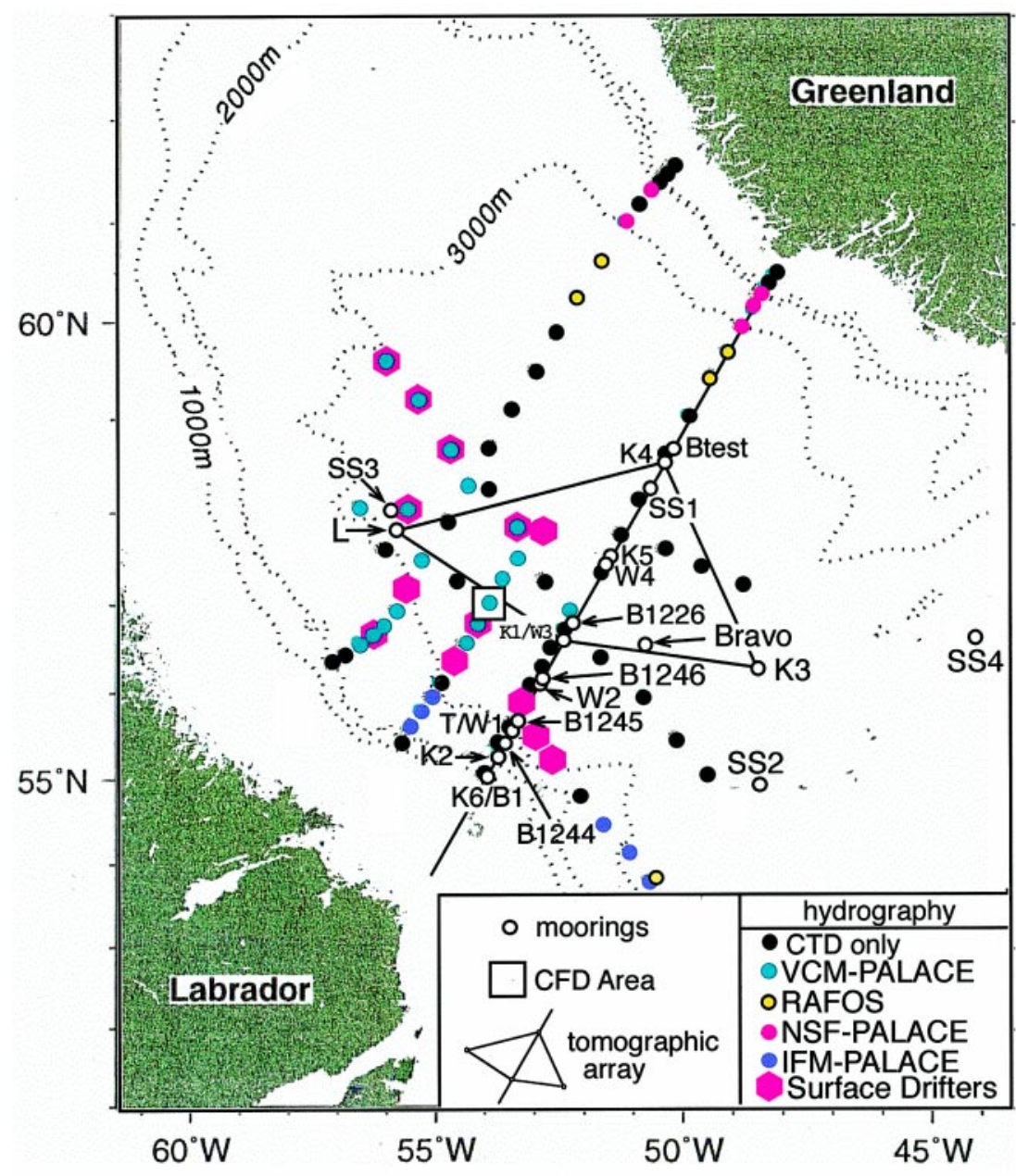

FIG. 9. Map showing elements of the oceanographic field program. The hydrographic stations occupied by the Knorr during February and March 1997 are indicated, as are the floats deployed from Knorr (colored symbols; see key). Also shown are the position of the moorings (open circles), the Central Float Deployment (CFD) region and the tomographic array. Many other floats were deployed in cruises both before and after that of the Knorr. The Ks indicate the position of Kiel moorings, the Bs are boundary current moorings, Ws are inverted echo sounders, and SSs are RAFOS sound sources. Investigators involved in the field program are indicated in Table 1.
Finally, freely drifting surface drifters and subsurface floats of various designs provided an economical way to measure a wide range of space and timescales. A large number $(>150)$ of such devices have been deployed (see Fig. 9). All measure horizontal velocity and temperature at their location; some measured vertical velocity, a clear signature of convection. Others periodically profiled the T/S structure of the water column, moving up to the surface and relaying data back to base before dropping down to their reference level again. A broad range of spatial scales was sampled by deploying the instruments in both small- and gyre-scale arrays.

\section{2) Atmosphere}

The fluxes of heat, moisture, and radiation across the air-sea interface are the primary agents responsible for the densification of the surface waters that triggers convection. The objective of the meteorological component of the experiment was to document the surface fluxes and to understand the mechanisms responsible for them. Our measurements benefited from the larger-scale context provided by the FASTEX experiment (Joly et al. 1997).

Historically, there have been no array of autonomous floats deployed as part of the WOCE Atlantic Circulation and Climate Experiment, which mapped out the large-scale circulation.

The three-dimensional structure of the Labrador Sea gyre was revealed by numerous hydrographic sections across the basin during four cruises in 1996-97. These three-dimensional data were complemented by acoustic tomography, measuring average properties between several moored acoustic transceivers (see Send et al. 1995). In addition, the WOCE AR-7 hydrographic section (see Fig. 9) was heavily instrumented with moorings measuring velocity, salinity, and temperature throughout the water column at high temporal resolution. direct measurements of the fluxes of heat, momentum, and moisture across the air-sea interface in the Labrador Sea-only bulk estimates. As a result, the confidence that one can have in model-derived estimates of these fluxes is reduced. It was therefore decided to collect in situ data during a winter oceanographic cruise of the R/V Knorr to test flux estimates of numerical models and observe the detailed evolution of the atmospheric boundary layer. Measurements of the fluxes of incoming solar radiation, momentum, sensible and latent heat, water vapor, and precipitation were carried out by a consortium of groups. To improve our understanding of the structure and evolution of weather systems over the region and to 
facilitate model initialization and verification efforts, radiosonde launches were also made from the Knorr. Table 2 outlines the wide variety of activities associated with the science program on the Knorr. In tandem with the ship program, several aircraft missions were flown to document the synoptic-scale environment over the region and to make measurements of the mesoscale structures that modulate air-sea interaction in the region.

There was also a remote sensing component to the experiment. Images were collected at prespecified times and locations from the Canadian Radar Satellite Synthetic Aperture Radar (SAR) and data were collected on an ad hoc basis from the European Satellite Agency European Remote-sensing Satellite-2 (ERS-2) SAR, scatterometer, and radar altimeter. Two well-equipped aircraft (a CV-580 from the Canada Centre for Remote Sensing and a P3 from NASA/ Goddard Space Flight Center) flew over the ship on separate 4-day missions collecting sea surface and mean meteorological profile data using a wide variety of instruments.

\section{b. Anticipating where convection will happen}

During the planning stages of the convection experiment we began to recognize that decadal climate variability reviewed in section $2 \mathrm{~b}$ and the vagaries of the NAO might interfere with our goal to observe deep convection in the Labrador Sea. The winter of 1993 had resulted in an extremely active convection season penetrating down to more than 2200-m depth, but in subsequent winters convection never reached those depths again and in fact the winter of 1995-96 resulted in convection that was probably no deeper than $1000 \mathrm{~m}$.

With the drop in the NAO index during the winter of 1995-96 we feared a second weak winter. It was clear that we had to make sure that the instruments designed to observe deep mixing were deployed in an optimum way. Luckily we were in a position to deploy deep mixed layer floats during the early part of the Knorr winter survey, just a few weeks prior to the expected deepest mixing. But where, precisely, should we put them?

Starting in October 1996 we began predicting several convection scenarios using both a high-resolution numerical model (Marshall et al. 1997) and real-time data coming in from some 30 profiling Autonomous Lagrangian Circulation Explorer (PALACE) floats, whose position in February 1997 is indicated in Fig. 10. The temperature and salinity profiles provided by these floats were used to compute the stratification and obtain estimates of how much buoyancy was held in the water column. This buoyancy content was compared to the expected buoyancy loss between the time of "forecasting" and the end of the winter season in late March, enabling us to predict how deep convection might reach assuming it to be a one-dimensional (1D) process. The expected depth to which the mixed layer would reach in a moderate winter (defined as one in which there was only $80 \%$ of a typical wintertime buoyancy loss) assuming nonpenetrative deepening, is indicated in Fig. 10. As reviewed in section 4a, early in the winter heat losses were relatively weak raising some concern, but our predictions suggested that we would still have a reasonable chance of observing mixing down to a depth of 800-1000 m. Nevertheless, it was decided to withhold half of the floats to be able to spread the risk over two convection seasons; the remainder were deployed in the second phase of the field work, in January 1998. By early January 1997 it became clear that an interesting pattern of stratification was revealed by the PALACE floats (see Fig. 10): the sea was strongly stratified to the north and to the south, but a band of weak stratification existed in the middle, some $3^{\circ}$ in width centered at $56^{\circ} \mathrm{N}$. Combining this information with the climatological distribution of oceanic heat loss that shows a maximum just eastward of the Labrador coast (see Fig. 4) we identified an area of weakest stratification and expected maximum heat loss (the "yellow" region in Fig. 10). This "prediction" also found support from the high-resolution numerical model of the Labrador Sea developed by C. Herbaut and J. Marshall (1998, personal communication) (see Fig. 11).

Based on the above considerations, a few days before the Knorr left Halifax, Nova Scotia, Canada, it was decided to deploy the floats in a central float deployment (CFD) area [the box marked in Fig. 9, roughly coinciding with the position of the convection patch observed by Clarke and Gascard (1983); also see the shaded patch in Fig. 1]. During early February the float array was deployed. From October until the middle of February our predictions of mixed layer depth, based on the assumption of a moderate winter, remained unchanged at 800-1000 m. However, to our great delight and as described in section $4 b$, by the end of the Knorr cruise (12 March) the mixed layer had reached a maximum depth of $1500 \mathrm{~m}$ in one spot $50 \mathrm{~km}$ southward of our best-guess estimate. The cyclonic circulation pattern over the North Atlantic had intensified during February, resulting in heat losses 
TABLE 2. Meteorological and air-sea flux measurements on R/V Knorr.

\begin{tabular}{|c|c|c|c|}
\hline Instrument & Variable(s) & Owner/Lab & PI \\
\hline Rawinsonde, 6-12 day & U,D,Td, Ta & Guest/NPGS & Guest/NPGS, IfM Kiel \\
\hline Solar pyranometer & $\mathrm{SW}+\mathrm{LW}$ incoming & Guest/NPGS & Guest/NPGS, IfM Kiel \\
\hline Laser ceilometer & CeilingHt, CloudHt & White/ETL & Guest/NPGS \\
\hline $3 \mathrm{GHz}$ precipitation radar & VertVel Liq. $\mathrm{H}_{2} \mathrm{O}$ & Costa/ETL & Dobson/BIO \\
\hline Ship rain gauge & $\mathrm{P}$ & Uhlig/Kiel & Uhlig/Kiel \\
\hline Disdrometer & $\mathrm{P}, \mathrm{P}^{\prime}$ & Grossklaus/Kiel & Uhlig/Kiel \\
\hline Disdrometer & $\mathrm{P}, \mathrm{P}^{\prime}$ & Hare/ETL & Dobson/BIO \\
\hline IR cloud temp & $\mathrm{T}_{\text {cloudbot }}$ & Uhlig/Kiel & Uhlig/Kiel \\
\hline IR sea temp & $\mathrm{Ta}$ & Guest/NPGS & Guest/NPGS \\
\hline "Sea snake" & $\mathrm{Ta}$ & Hare/ETL & Dobson/BIO \\
\hline Intake temp & $\mathrm{Ta}$ & IMET/WHOI & Pickart/WHOI \\
\hline Pl. res. therm. & $\mathrm{Ta}$ & Hare/ETL & Dobson/BIO \\
\hline Thermistor & $\mathrm{Ta}$ & IMET/WHOI & Pickart/WHOI \\
\hline Fast thermometer & $\mathrm{Ta}, \mathrm{Ta}^{\prime}$ & Bumke/Kiel & Uhlig/Kiel \\
\hline Thermistor & $\mathrm{Ta}, \mathrm{Ta}^{\prime}$ & Anderson/BIO & Anderson/BIO \\
\hline Thermistor & $\mathrm{Ta}, \mathrm{Ta}^{\prime}$ & Anderson/BIO & Anderson/BIO \\
\hline Hygrometer & $\mathrm{RH}$ & IMET/WHOI & Pickart/WHOI \\
\hline Dewflinger & $\mathrm{e}^{\prime}$ & Aktaturk/UW & Anderson/BIO \\
\hline Hygrometer & $\mathrm{h}^{\prime}, \mathrm{CO}_{2}^{\prime}$ & Hare/ETL & Anderson/BIO \\
\hline Wind monitor & $\mathrm{U}, \mathrm{D}, u^{\prime}, \mathrm{d}^{\prime}$ & Anderson/BIO & Anderson/BIO \\
\hline Gill sonic anem. & $\mathrm{U}, \mathrm{D}, \mathrm{Ta}, u^{\prime}, v^{\prime}, w^{\prime}, \mathrm{ta}^{\prime}$ & Anderson/BIO & Anderson/BIO \\
\hline Anemometer & $\mathrm{U}, \mathrm{D}, \mathrm{Ta}, u^{\prime}, v^{\prime}, w^{\prime}, \mathrm{ta}^{\prime}$ & Bumke/Kiel & Bumke/Kiel \\
\hline Motion package & $\mathrm{a}_{\mathrm{i}}$, Tilt $_{\mathrm{i}}$ & Uhlig/Kiel & Uhlig/Kiel \\
\hline Gyrocom-pass & Ship's course & IMET/WHOI & Pickart/WHOI \\
\hline Gyrocom-pass & Ship's course & Hare/ETL & Dobson/BIO \\
\hline Doppler log & Ship's speed & IMET/WHOI & Pickart/WHOI \\
\hline GPS & Ship's position & IMET/WHOI & Pickart/WHOI \\
\hline Marine radar & Wave field & Trizna/NRL & Dobson/BIO \\
\hline Wave height gauge & Wave height & Dobson/BIO & Dobson/BIO \\
\hline Directional buoy & Wave dirn. spec & Dobson/BIO & Dobson/BIO \\
\hline
\end{tabular}

Caps = Mean quantities; primes = fluctuations about the means; $\mathrm{U}, \mathrm{u}=$ wind speed $\mathrm{D}, \mathrm{d}=$ wind direction; $\mathrm{v}, \mathrm{w}=\mathrm{wind}$ components crosswinds, vertical; $\mathrm{Ta}=$ air temperature; $\mathrm{Ts}=$ sea surface temperature; $\mathrm{h}=$ absolute humidity $\mathrm{CO}_{2}=\mathrm{CO}_{2}$ content; $\mathrm{a}=$ acceleration; $\mathrm{P}=$ precipitation; $\mathrm{e}=$ water vapor; $\mathrm{IMET}=$ improved meteorological measurement system; $\mathrm{Pl}$. res. therm. = platinum resistance thermometer.

$\mathrm{ETL}=$ Environmental Technology Laboratory, NOAA; NPGS = Naval Postgraduate School. 
greatly exceeding climatological values (see section 4a), which induced deeper-than-expected convection.

\section{Preliminary results from the 1996-97 experiment}

a. The atmospheric forcing during the winter of 1997

1) SyNoptic CONDITIONS DURING WINTER 1997

The winter of 1997 provided an excellent opportunity to document the variability in the air-sea interaction that exists within a given winter season. Figure 12 shows the average mean sea level pressure, 10-m wind, and total heat flux fields for January 1997 (Fig. 12a) and February 1997 (Fig. 12b) as determined from the NCEP-NCAR Reanalysis project. A comparison between the two months and the winter climatology (Fig. 5) shows that a dramatic transition occurred in the flow regime over the North Atlantic and that this resulted in a significant change in the magnitude of the surface cooling in the Labrador Sea region. January 1997 was a month in which the circulation over the North Atlantic was significantly different from the winter climatology; the presence of a blocking high over Europe and anomalously strong high pressure over Greenland resulted in a significant westward shift in the center of cyclonic activity. It is interesting to note that even with this weakening of the cyclonic flow over the North Atlantic, the mean total heat loss in the center of the Labrador Sea was, at $260 \mathrm{~W} \mathrm{~m}^{-2}$, larger than the climatological winter mean. In contrast, February 1997 was a month in which the circulation pattern over the North Atlantic was significantly stronger than average. As one might expect in such a flow configuration, the mean heat loss in the center of the Labrador Sea, some $420 \mathrm{~W} \mathrm{~m}^{-2}$, was significantly above the climatological winter mean (see Table 3). These extremely high oceanic heat losses contributed to making what might otherwise have been a lackluster winter, from the perspective of forcing deep convection, into a "good" winter.

\section{2) VARIABILITY IN HEAT AND MOISTURE FLUXES} DURING THE WINTER OF 1997

Although a period of one month is a convenient period of time over which to average, the influence and phasing of individual events tends to be lost by such averaging. Another and perhaps more illuminating view of the variability of air-sea interaction in the Labrador Sea during the winter of 1997 is depicted in Fig. 13. This figure shows the 6-hourly values of mean sea level pressure at a location in the center of the climatological Icelandic Low $\left(62^{\circ} \mathrm{N}, 30^{\circ} \mathrm{W}\right.$; Fig. 13a) and total heat flux at the Bravo site $\left(56^{\circ} \mathrm{N}, 51^{\circ} \mathrm{W}\right.$; Fig. $\left.13 \mathrm{~b}\right)$ as determined from the NCEP-NCAR Reanalysis. It is clear that the North Atlantic flow regime in December 1996 and early January 1997 was significantly different from that in the latter part of the winter. The generally high sea level pressure and weak cyclonic activity in the early part of the winter can be classi-

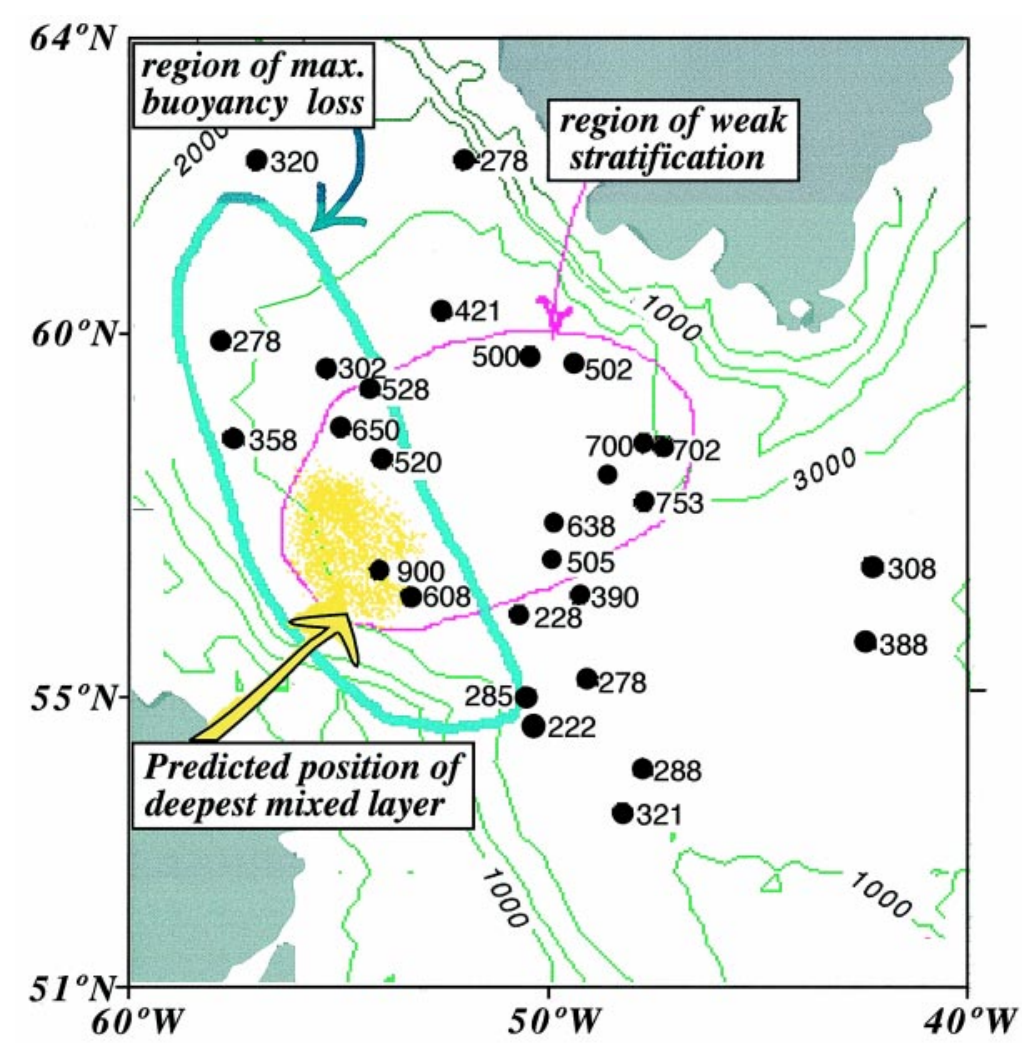

FIG. 10. Position of PALACE floats (black discs; courtesy of R. Davis) at the beginning of February 1997. Based on the measured buoyancy content in the water column at these positions, climatological estimates of the buoyancy loss from the surface, estimates of the expected maximum depth of the mixed layer are indicated in meters (courtesy of M. Visbeck) assuming a moderate winter (defined as $80 \%$ of the climatology), and a $1 \mathrm{D}$, nonpenetrative process. The region of weakest stratification is marked. Its overlap with the region of maximum buoyancy loss to the atmosphere led to our prediction of the position of deepest mixed layer depth (marked yellow). This, together with the numerical model results shown in Fig. 11, guided our choice of position of the CFD area. 


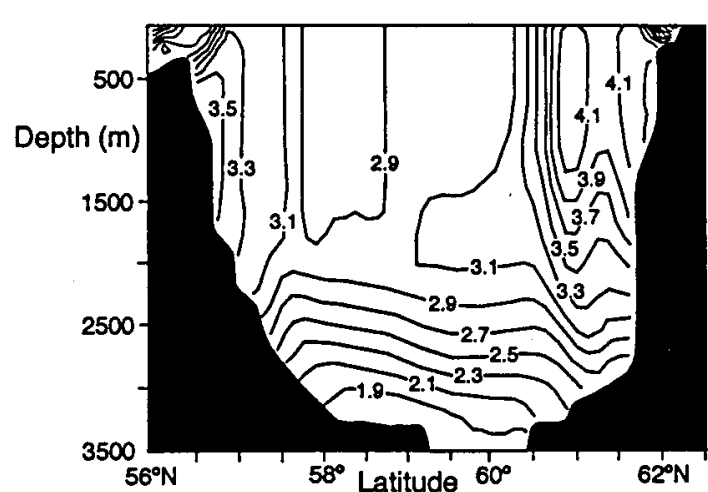

(a)

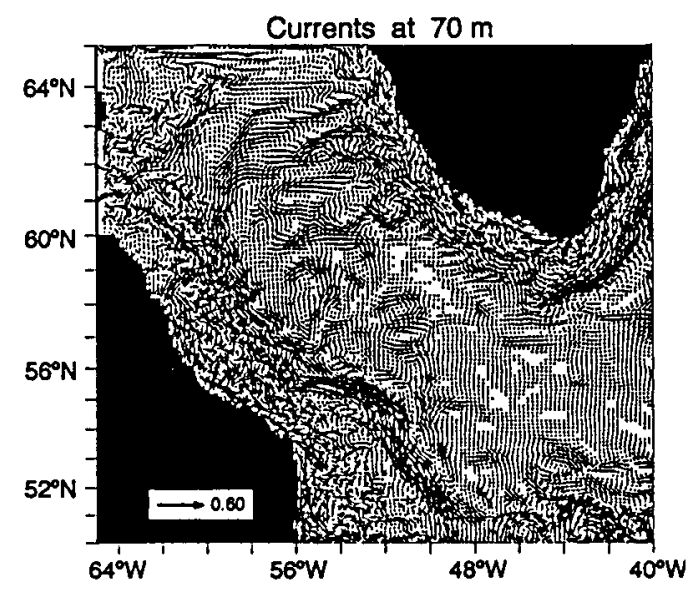

(b)

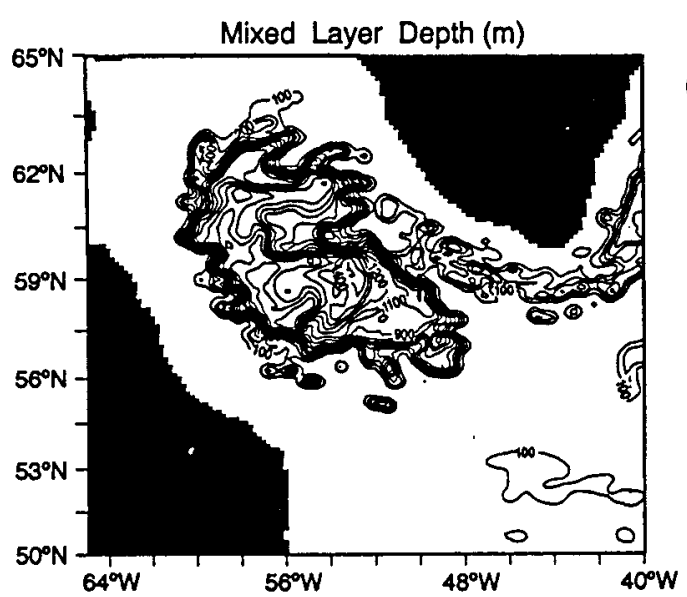

FIG. 11. Simulation of water mass transformation in a highresolution model of the Labrador Sea developed by C. Herbaut and J. Marshall (1998, personal communication): (a) hydrographic section of temperature across the model's AR-7 section, (b) currents at a depth of $100 \mathrm{~m}$ showing the boundary current and eddies, and (c) mixed layer depth in March 1992 obtained by driving the model with NCEP winds and fluxes starting in summer 1991. The position of the region of deepest mixed layer is roughly coincident with that indicated in Fig. 10.

fied, according to Vautard (1990), as being associated with either a "blocking" or "Greenland anticyclone" regime, while the low sea level pressure and strong cyclonic activity during the latter part of the winter belongs to a more "zonal" flow regime. The first two weeks of January were unusual in that the pressure near Iceland underwent a monotonic decrease. This change in flow regime had a dramatic impact on the surface cooling that was taking place in the Labrador Sea. From December 1996 to 15 January 1997 the average total heat flux at the Bravo site was only $150 \mathrm{~W} \mathrm{~m}^{-2}$. Indeed, the lowest heat fluxes occurred during the first two weeks of January. Over the flowing six-week period ending on 28 February 1997, however, it was in excess of $420 \mathrm{~W} \mathrm{~m}^{-2}$ with peak fluxes greater than $1000 \mathrm{~W} \mathrm{~m}^{-2}{ }^{1}$ There is significant high-frequency variability in the magnitude of the total heat flux, a signature of the passage of North Atlantic cyclones. This can be seen from the high degree of anticorrelation that exists between the two time series (see Fig. 13). Furthermore, the data explain why the surface cooling during January was above the climatological mean even though the monthly mean sea level pressure field indicated a weaker than average cyclonic flow over the North Atlantic. The more vigorous cyclonic circulation that developed after the middle of the month and the concomitant elevated heat fluxes led to a large monthly mean heat flux for January.

With a few exceptions, the time series of precipitation is similar to that of the total heat flux. The highest precipitation rates, in excess of $2 \mathrm{~mm} \mathrm{~h}^{-1}$, occurred in late January and February. A careful examination of the phasing of the precipitation and total heat flux maxima in the Labrador Sea region indicates that the former typically leads the latter by approximately one day. This is a consequence of the structure of a typical extratropical cyclone, such as the one shown in Fig. 2, which results in a separation of the region of high precipitation from that of high heat flux.

Table 3 presents monthly mean values of the total heat flux from NCEP-NCAR, precipitation rate, and net radiative flux at the historic location of the Ocean Weather Station Bravo $\left(56^{\circ} \mathrm{N}, 51^{\circ} \mathrm{W}\right)$ for the months of December 1996, and January, February, and March 1997. December 1996 was a month in which the fluxes of heat and momentum were anomalously low, when compared to the 30-yr mean for the month of December. In contrast, January and February 1997 were months in which these fluxes exceeded the 30-yr means. When considered as a whole, the winter of

${ }^{1}$ It is important to note that there is a clear discrepancy between analyzed fluxes and the bulk estimates from the Knorr; compare Fig. 14 with Fig. 13, for example. Are they real or the result of differences in sampling or of reporting? 
1997 was one in which the fluxes of heat, moisture, and net radiation exceeded the $30-y r$ means by approximately one standard deviation and so was highly conducive to convective activity in the Labrador Sea region.

\section{3) Aircraft and Remote SENSING MISSIONS}

The meteorological aircraft studies consisted of three missions over the Labrador Sea. Flight planning took into account the position of the Knorr and meteorological conditions reported from the ship, and on one occasion sampling took place in the vicinity of the ship. The flights were completed during February 1997 with research aircraft from the 53d Weather Reconnaissance Squadron of the U. S. Air Force. The C-130 aircraft used were equipped with dropsonde systems and were able to record state parameters at flight level. To assist in flight planning, as described in Renfrew et al. (1998), the Naval Research Laboratory ran a special version of their Coupled Ocean-Atmosphere Mesoscale Prediction System (COAMPS) (see Hodur 1997) regional atmospheric forecast model over a domain that included the Labrador Sea twice daily out to $36 \mathrm{~h}$. The model data, including all important surface fields such as the heat, radiative, and moisture fluxes, were made available in real time to scientists in the field, greatly helping the planning process. These data were also used to generate daily synoptic weather summaries and forecasts for use by the Knorr in scheduling operational and scientific ship activities.

Two remote sensing aircraft programs were carried out over the Knorr during the experiment. On 22-24 February a Convair 580 from the Canada Centre for Remote Sensing equipped with a C-band synthetic aperture radar flew a series of four missions, imaging the ship and the waters around her to determine the effects of polarization on the ability of the instrument to image the sea surface. On 3-9 March a P-3 aircraft from NASA flew four ocean wave imaging and passive microwave missions over the ship. Both missions carried out intensive surface meteorological and wave measurements in concert with the shipboard measurement program. In addition, ERS-2 SAR images of the ocean surface were obtained and attempts made to identify the surface signature of deep ocean convection by using hydrodynamic models of convection and a sensor model for SAR (see Fischer et al. 1998). Identification of a convective surface signature could allow unique information about the spatial characteristics of the convective process to be determined such as the extent of convecting region, the size of individual convective plumes and eddies, the ratio of converging to diverging area, and the surface current strain. Initial results, though speculative 
TABLE 3. Fluxes and precipitation from the NCEP-NCAR Reanalysis.

\begin{tabular}{|c|c|c|c|c|c|}
\hline & $\begin{array}{c}\text { Dec } \\
1996\end{array}$ & $\begin{array}{c}\text { Jan } \\
1997\end{array}$ & $\begin{array}{c}\text { Feb } \\
1997\end{array}$ & $\begin{array}{l}\text { Mar } \\
1997\end{array}$ & $\begin{array}{c}\text { Winter of } \\
1997\end{array}$ \\
\hline $\begin{array}{l}\text { Total heat flux }\left(\mathrm{W} \mathrm{m}^{-2}\right) \\
(30-\mathrm{yr} \text { mean and } \\
\text { standard deviation })\end{array}$ & $\begin{array}{c}117 \\
(189 \pm 64)\end{array}$ & $\begin{array}{c}258 \\
(223 \pm 91)\end{array}$ & $\begin{array}{c}422 \\
(247 \pm 98)\end{array}$ & $\begin{array}{c}227 \\
(198 \pm 88)\end{array}$ & $\begin{array}{c}271 \\
(223 \pm 59)\end{array}$ \\
\hline $\begin{array}{l}\text { Precipitation rate }\left(\mathrm{mm} \mathrm{h}^{-1}\right) \\
(30-\mathrm{yr} \text { mean and } \\
\text { standard deviation) }\end{array}$ & $\begin{array}{c}0.114 \\
(0.167 \pm 0.043)\end{array}$ & $\begin{array}{c}0.247 \\
(0.162 \pm 0.050)\end{array}$ & $\begin{array}{c}0.175 \\
(0.137 \pm 0.046)\end{array}$ & $\begin{array}{c}0.192 \\
(0.114 \pm 0.039)\end{array}$ & $\begin{array}{c}0.182 \\
(0.147 \pm 0.028)\end{array}$ \\
\hline $\begin{array}{l}\text { Net radiative flux }\left(\mathrm{W} \mathrm{m}^{-2}\right) \\
(30-\mathrm{yr} \text { mean and } \\
\text { standard deviation })\end{array}$ & $\begin{array}{c}53.2 \\
(57 \pm 7)\end{array}$ & $\begin{array}{c}50.8 \\
(55 \pm 10)\end{array}$ & $\begin{array}{c}44.8 \\
(25+10)\end{array}$ & $\begin{array}{c}-20 \\
(-25 \pm 7)\end{array}$ & $\begin{array}{c}32 \\
(28 \pm 5)\end{array}$ \\
\hline
\end{tabular}

Mean values of the total heat flux $\left(\mathrm{W} \mathrm{m}^{-2}\right)$, precipitation rate $\left(\mathrm{mm} \mathrm{hr}^{-1}\right)$ and net radiative flux $\left(\mathrm{W} \mathrm{m}^{-2}\right)$ at $56^{\circ} \mathrm{N}, 51^{\circ} \mathrm{W}$ for the months of December 1996 and Jan-Mar 1997 as diagnosed from the NCEP-NCAR Reanalysis. Also shown are the means for the winter of 1997 (1 Dec-31 Mar 1996 inclusive). The 30-yr means for the various time periods as well as the standard deviation from the means are also shown.

in nature, showed several scenes that had an appearance that mimicked model results.

\section{4) IN SITU MEASUREMENTS FROM THE KNORR}

The R/V Knorr was in the Labrador Sea proper from 7 February to 12 March 1997. During that period the atmospheric conditions were surprisingly consistent and in the "zonal regime". Most of the low-pressure systems that approached from the south and west tracked to the south of the ship, and for virtually the entire cruise the wind direction was westerly to northerly. Upper-air winds were generally from the west. We were in a "cold air outbreak" regime (see Figs. 2 and 12b).

At this early stage in the analysis what is really available to us, besides real-time uncalibrated estimates of the fluxes from our on-line logging systems, are bulk flux estimates and the evidence of our senses. They tell us that the entire period was dominated by a flow of cold dry air from the northwest, intense transfers of heat and water vapor to the atmosphere, everpresent precipitation in the form of snow squalls, and rapid deepening of the oceanic mixed layer. Table 4 indicates the ranges and types of meteorological conditions encountered during the cruise.

Figure 14 is a plot of preliminary time series of airsea fluxes as deduced from heat and momentum transfers encountered during the cruise of the Knorr. (The bulk meteorological parameters on which they are based have not been fully corrected, although the

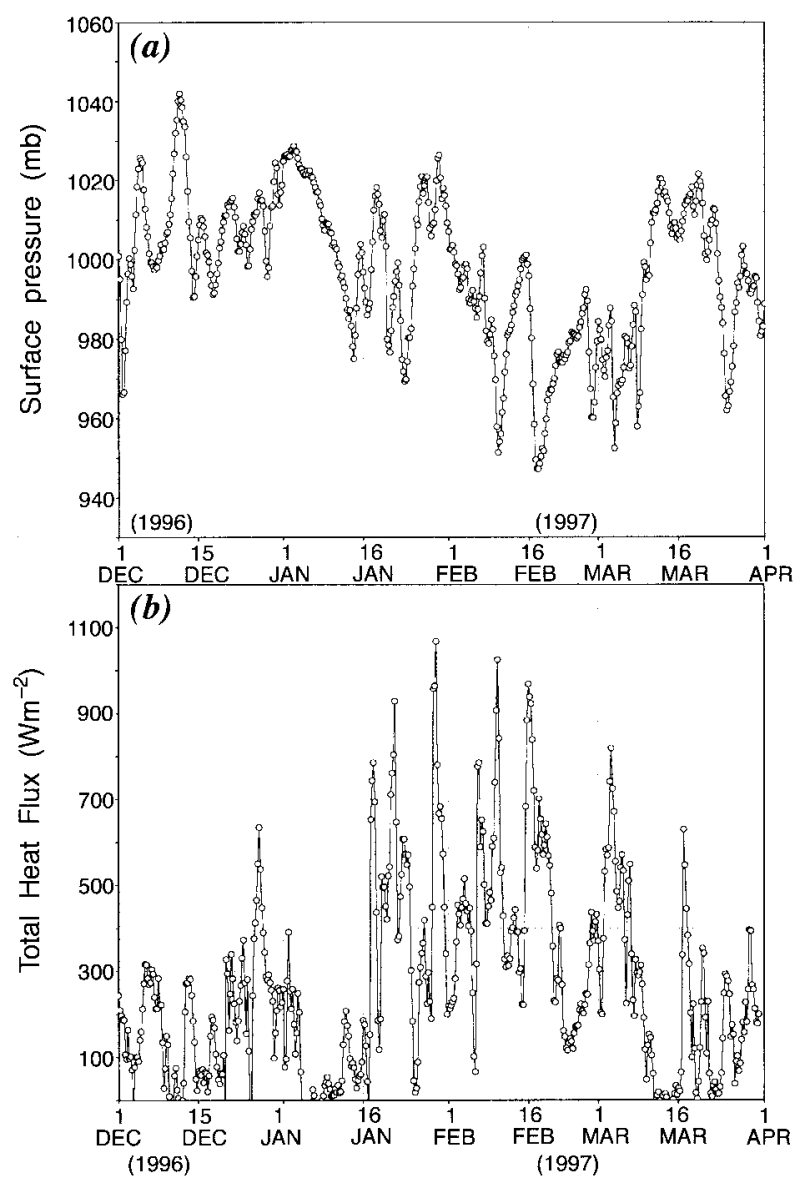

FIG. 13. (a) Six-hourly valves of mean sea level pressure (mb) at $62^{\circ} \mathrm{N}, 30^{\circ} \mathrm{W}$ and (b) total heat flux $\left(\mathrm{W} \mathrm{m}^{-2}\right)$ at $56^{\circ} \mathrm{N}, 51^{\circ} \mathrm{W}$ for the period 1 December 1996-1 April 1997 as determined from the NCEP-NCAR Reanalysis. 
winds have been transformed from relative to the ship into absolute.) We have made no attempt to separate the data into periods when the ship was still or moving, so the time series is a mix of time and space. The large heat fluxes to the atmosphere are a reflection of the environment the ship was working in, but note that they are somewhat smaller than those implied by the models (see Fig. 13). They are largest in magnitude at times when the ship approached the ice pack on the Labrador coast.

It is interesting to use the average of the total heat flux to compute the cooling effect of the fluxes themselves. Assuming that a layer of ocean $1000 \mathrm{~m}$ deep was cooled over the course of the Knorr's stay in the Labrador Sea, the average flux of $360 \mathrm{~W} \mathrm{~m}^{-2}$ would have cooled that water by about $0.24^{\circ} \mathrm{C}$. This is a representative calculation only, being a combination of the fluxes at different locations in the Labrador Sea at different times. Nevertheless, the heat loss as measured by the CTD was very close to what would be expected based on the ship measurements.

Estimates of mean evaporation $\mathrm{E}$ and precipitation $\mathrm{P}$ for the period are incomplete at time of writing and hence inaccurate. Based on the bulk latent heat flux from Table 4, E is about $5 \mathrm{~mm} \mathrm{day}^{-1}$; based on visual estimates of snow accumulation rates on deck, $\mathrm{P}$ is $5-15 \mathrm{~mm} \mathrm{day}^{-1}$, in both cases of liquid water. We intend to improve both, using eddy correlation latent heat fluxes for $\mathrm{E}$ and disdrometer measurements for $\mathrm{P}$.

Heat was lost over the entire sea, but by different mechanisms in different parts of the area. Near the western boundary, the precipitation was at a minimum but the measured upward fluxes of heat and water vapor were the largest. The snow squalls occupied more of the total surface area as we progressed eastward, so that from one-third of the way from the west to the east side it snowed more or less continuously. Whereas the net moisture transfer was upward on the western side, it was downward over most of the remainder of the area. This downward flux of moisture as precipitation was necessarily accompanied by an upward transfer of heat, since the water that received the snow had to give up the latent heat of fusion as well as some sensible heat. Thus there was upward transfer of heat over the entire sea, but the flux of buoyancy was upward on the western side and downward to the east. Using a bulk surface heat flux method (Smith 1988), the average sensible heat flux during the time the ship was in the Labrador Sea proper was about $160 \mathrm{~W} \mathrm{~m}^{-2}$. The average latent heat flux was about $150 \mathrm{~W} \mathrm{~m}^{-2}$.

The spatial distribution of observed heat and moisture transfer suggests that at least during cold air outbreaks (northwesterly winds), the Labrador Sea forces a strong coupled response in the atmosphere and that the air-sea transfers ensure that the entire atmosphereocean system can be treated (and modeled) as a single coupled process. However, when the wind is from the south (a rare occurrence over the duration of the cruise) there is a ready supply of warm advective moisture for precipitation.

In addition to surface atmospheric measurements, many upper-air rawinsonde profiles were performed from the Knorr, the only rawinsonde measurements ever undertaken in the central part of the Labrador Sea. The upper-air profiles demonstrated that deep convection existed in the atmosphere as well as in the ocean. Figure 15 shows three examples: the deepest atmosphere boundary layer (ABL) observed during the cruise (0500 UTC 9 February), a more typical boundary layer in the same location a few hours later (1400 UTC 9 February), and a relatively shallow ABL 
TABLE 4. Range of meteorological conditions encountered during Knorr cruise.

\begin{tabular}{lcccc}
\hline & Min & Max & Mean & Std dev \\
\hline Air pressure (mb) & 973.1 & 1017.3 & 994.9 & 10.3 \\
\hline Wind speed (m s $\left.{ }^{-1}\right)$ & 0.4 & 24.7 & 11.7 & 3.9 \\
\hline Wind direction & & & 291 & \\
\hline Air temp ( $\left.{ }^{\circ} \mathrm{C}\right)$ & -17.11 & 4.15 & -7.84 & 3.80 \\
\hline Sea sfce temp $\left({ }^{\circ} \mathrm{C}\right)$ & -1.47 & 5.72 & 2.89 & 5.72 \\
\hline Relative humidity $(\%)$ & 42.0 & 95.8 & 68.7 & 9.0 \\
\hline Wind stress $(\mathrm{Pa})$ & 0.0009 & 1.274 & 0.274 & 0.180 \\
\hline Sens heat flux & -15.6 & 374.2 & 163.5 & 79.9 \\
\hline Latent heat flux & -1.8 & 305.1 & 147.1 & 54.8 \\
\hline Net SW rad flux & -524.3 & 0.0 & -33.1 & 61.7 \\
\hline Net LW rad flux & 11.0 & 174.0 & 84.3 & 24.7 \\
\hline Net rad flux & -422.1 & 165.7 & 51.1 & 62.9 \\
\hline Total heat flux & -255.3 & 732.7 & 361.7 & 160.8 \\
\hline
\end{tabular}

Notes:

1. These statistics are based on 5-min averages of the 15-s samples of the Knorr's IMET system (sensor height $23 \mathrm{~m}$ ) and samples from the U.S. Naval Postgraduate School's radiation measurement system. They cover only the period from 0000 UTC on 8 Feb 1997 until 24 UTC on Mar 13, when the Knorr was actually in the experimental area.

2. All heat fluxes are in $\mathrm{W} \mathrm{m}^{-2}$, and positive upward (out of the ocean).

$b$. The response of the ocean

1) WINTER CRUISE: 7 FEB-12 MARCH 1997

(i) Hydrography

The planned cruise track was designed to cover a broad area of the Labrador basin, with emphasis on the western sector (see Fig. 9). After repeating the along-basin section of the fall cruise (October-November 1996) it was evident that the developing region of deepest convection was of limited lateral extent. Cross-basin sections were thus placed more closely together, and "dog-legs" devised in order to achieve a broad coverage (Fig. 9). We ensured that detailed boundary crossings were made on both sides of the basin (on the Labrador side these were limited by the ice pack) so that the role of the warmsalty Irminger water on both the convection and restratification process could be addressed. The central crossbasin section, where the deepest mixed layers were observed, was repeated a second time in order to shed light on the relative influence of vertical versus horizontal advection. Finally, we performed two detailed fine resolution CTD surveys, the second of which captured the deepest convection of the experiment $(1500 \mathrm{~m})$.

There were numerous surprises that will require further analysis using the combined resources of the convection

just downwind of the ice edge (22 February). In general, the ABL tended to be shallowest just off the upwind ice edge (as in the 22 February case) and it deepened rapidly offshore. However, considerable temporal variability (e.g., see the two 9 February profiles plotted in Fig. 15) prevented a detailed assessment of spatial variations in ABL characteristics from the ship data alone. One of the significant effects of the deep ABLs was that the temperatures and humidities required considerable time to adjust to the sea surface conditions due to the large quantity of air that had to be modified. Evidently, in cold air outbreaks over the Labrador Sea, the temperatures and humidities remain low and large turbulent sensible and latent heat fluxes extend all the way across the Labrador Sea. experiment. The rapidity at which the oceanic mixed layer deepened during the cruise was impressive. One of the CTD stations on the central cross-basin section was repeated three times during the 5-week period. A simple 1D mixed layer model (Pickart and Smethie 1998) required a sustained forcing of $1000 \mathrm{~W} \mathrm{~m}^{-2}$ to produce the observed mixed layer depths of the second and third occupations. This buoyancy loss is significantly greater than that observed, suggesting that the mixed fluid must have been advected from elsewhere to the point at which it was observed. Another surprise was how close convection occurred to the western boundary. In fact, the deepest observed mixed layers were near the $3100 \mathrm{~m}$ isobath, close to the core of the deep western boundary current with important ramifications for the spreading process. One view is 
that convection occurs in the center of the western cyclonic gyre (e.g., Clarke and Gascard 1983), then slowly spreads outward, predominantly by the action of baroclinic instability (Legg and Marshall 1993; Visbeck et al. 1996). Instead our observations suggest that some of the convected water may directly penetrate the western boundary current, thereby providing a swift escape route to southern latitudes. The increased surface salinity near the boundary, influenced by the Irminger water, may also play a role in the deep mixed layers observed there.

Throughout, the convection was observed to be accompanied by deformation-scale $(\sim 10 \mathrm{~km})$ geostrophic eddies and baroclinic instability. Toward the end of the cruise, particularly during the repeat of the central cross-basin section (see Fig. 9), we surmise that measurements were conducted during or shortly after active convection. The spatial variability in the CTD casts was remarkable. Intrusions were prevalent, and often the downcast trace would differ significantly from that of the upcast. Our second CTD tow-yo survey captured the capping-over of a convective patch, complete with numerous such intrusions. Some of this rich structure may be due to the proximity of convection to the boundary, where strong contrasts exist between resident water masses. Finally, we found that the region of deep convection was rather confined laterally, as revealed by the distribution of observed mixed layer depth (Fig. 16). This map is aliased in time with, for example, a ridge of shallow mixed layer depth corresponding to the along-basin section, which was occupied early in the cruise. Eventually this map will be adjusted for synopticity using all the available time series information. The relative importance of atmospheric forcing versus oceanic precondition-

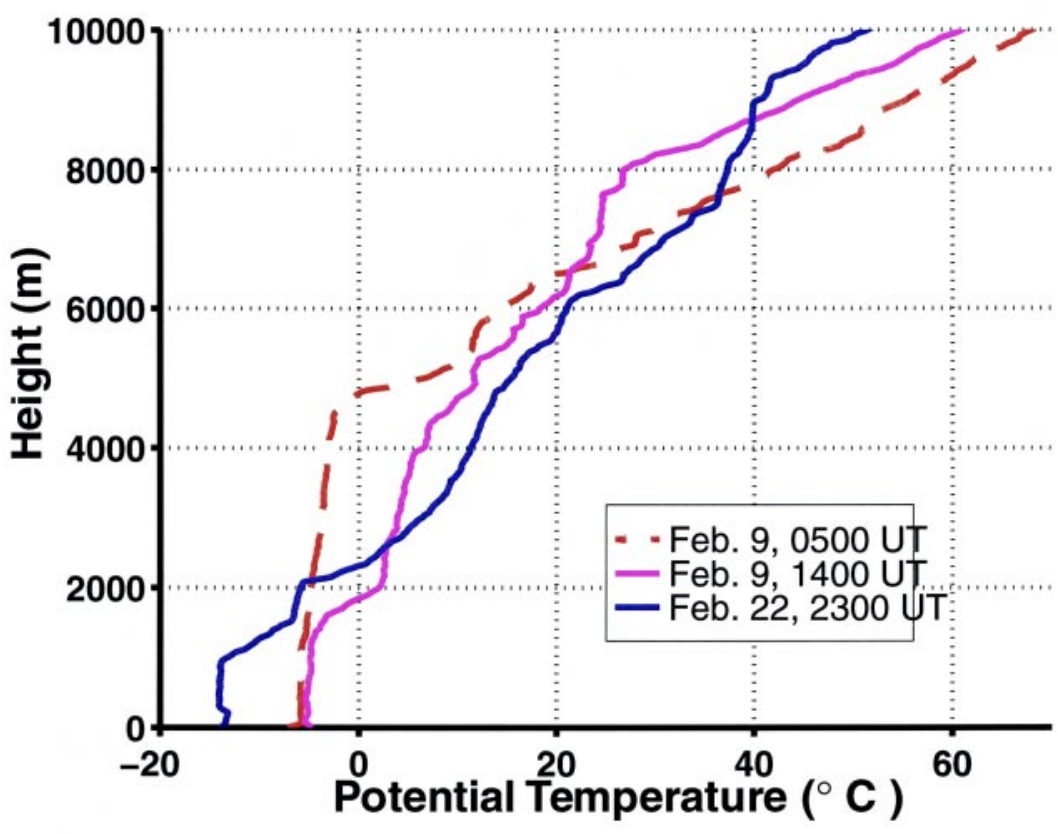

FIG. 15. Potential temperature vs height from the 1997 Knorr Labrador Sea cruise based on rawinsonde (weather balloon) profiles. Regions of near-constancy of potential temperature with height are indicative of convection in the atmospheric boundary layers. The potential temperature of 0500 UTC 9 February increases slightly between 1200 and $4500 \mathrm{~m}$ (following a "pseudo-adiabat") due to latent heat release within a cloud, but is indicative of a well-mixed layer of depth $\sim 4 \mathrm{~km}$ forming the ABL. The ABL depths on 1400 UTC 9 Feb and 2300 UTC 22 Feb are 1250 and $980 \mathrm{~m}$, respectively (courtesy of $\mathrm{P}$. Guest).

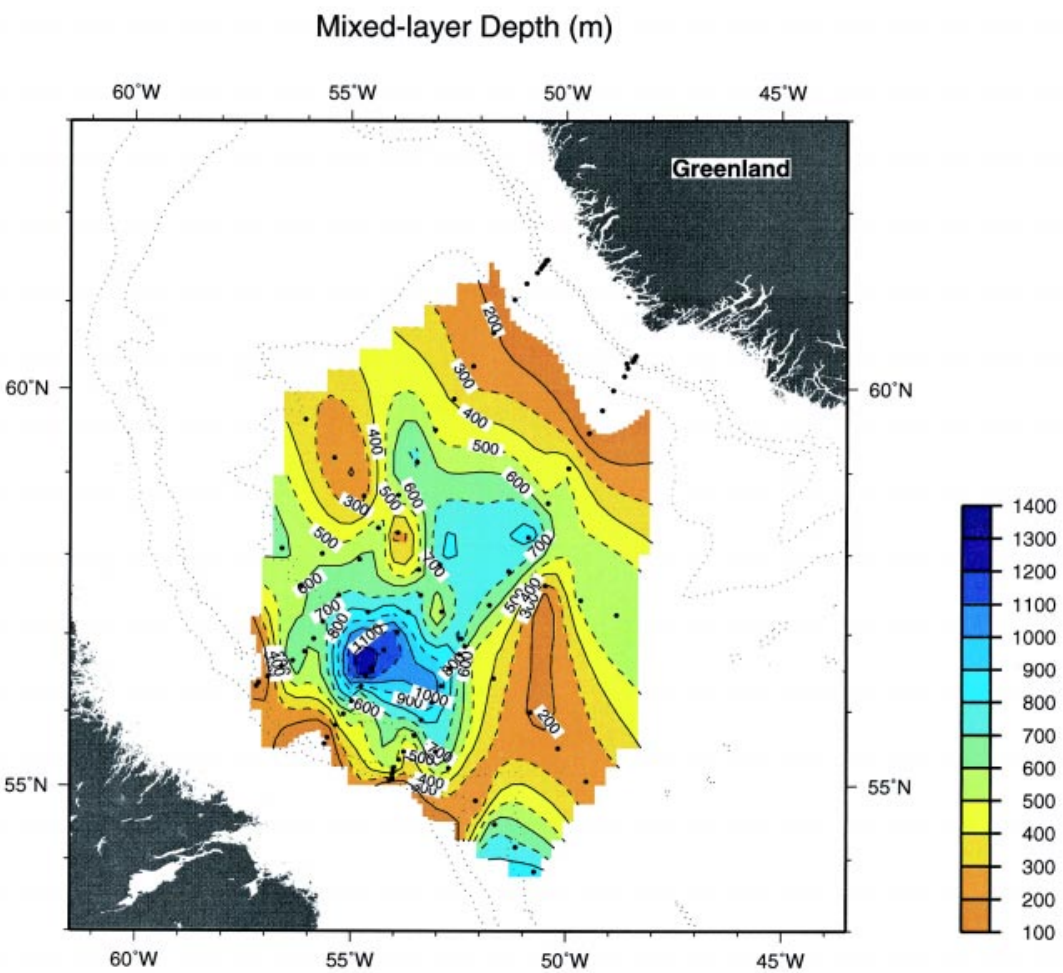

FIG. 16. Mixed layer depth deduced from the Knorr hydrography, an average over the period 7 February-12 March 1997. The deepest convection is localized to the west, where a mixed layer of depth $1100 \mathrm{~m}$ is observed (courtesy of R. Pickart). 
ing in setting the relatively confined scale of the mixed patch needs to be addressed.

\section{(ii) Tracers}

The chlorofluorocarbons (CFCs) CFC-11, CFC-12, and CFC-113 were measured at 44 of the hydrographic stations and provide a vivid record of

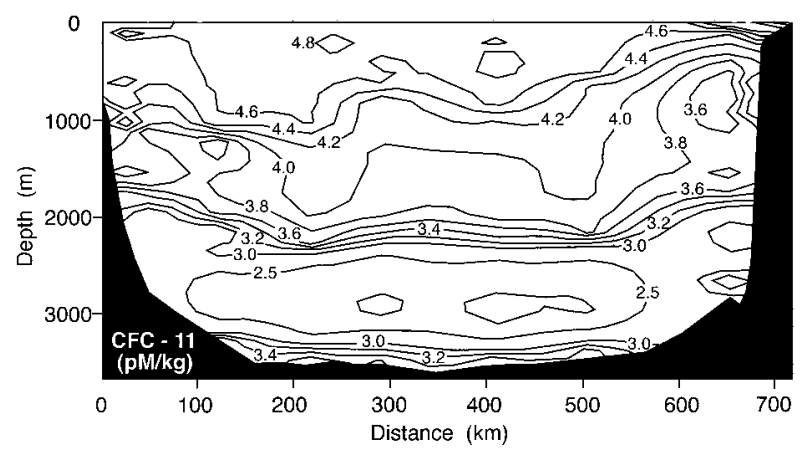

FIG. 17. Vertical distribution of CFC-11 (pmol kg-1) alongline AR7 of the Knorr winter Labrador Sea cruise. The data are preliminary, based on shipboard calculations (courtesy of W. Smethie).

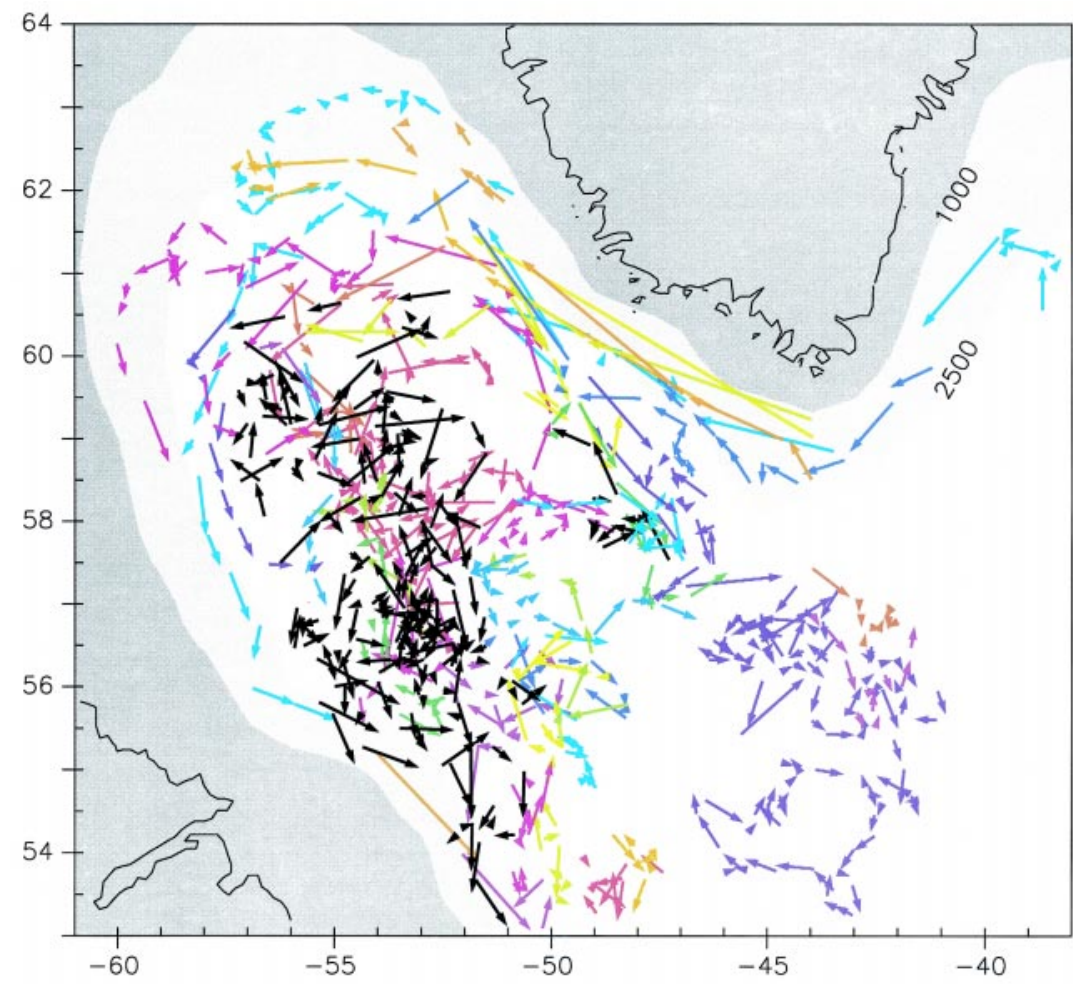

FIG. 18. The trajectories PALACE floats in the Labrador Sea. Colored vectors indicate submerged displacements over 10-20 days of floats drifting between 600 and 1500 m deployed between 1994 and 1997. Black vectors indicate the submerged displacement of VCM floats deployed near $400 \mathrm{~m}$ as part of the Convection ARI. These are 4-day displacements (courtesy of R. Davis). convective activity. CFCs enter the ocean at the surface and become incorporated in LSW during the deep convective process. In Fig. 17 the basin-scale distribution of CFCs is shown along the AR7 section (see Fig. 9 for position). The highest surface water CFC concentrations, close to equilibrium with the atmosphere, were observed at the margins of the Labrador Sea where convection was not occurring. In the central Labrador Sea, surface water concentrations were lower and well below equilibrium with the atmosphere as a result of deep convection transporting CFCs downward faster than they entered the surface water by gas exchange. LSW is readily identifiable in the CFC distribution as two distinct homogeneous layers, an upper layer extending from the surface to 500 1000-m depth and a deeper layer extending from the base of the upper layer to a depth of about $2200 \mathrm{~m}$. The upper layer is LSW that has just formed, deeper on the western side of the section. The deeper layer was formed during a previous winter when convection reached to $\sim 2 \mathrm{~km}$, probably in February and March 1992, as discussed in section $2 b$.

\section{2) FLOATS}

(i) Profiling floats (PALACE) and vertical current meters (VCM)

These floats periodically dive to depths near $1600 \mathrm{~m}$ collecting profiles of temperature and salinity. By adjusting buoyancy, the float then moves to a preprogrammed depth of either 1500 or $600 \mathrm{~m}$ where it follows currents for periods of 10 or 20 days. It then rises to the surface for $24 \mathrm{~h}$ during which time profile data is relayed to Argos satellites, which also locate the float. After this surface period, the only time when float position is known, the instrument descends to collect another profile and velocity observation.

Figure 18 shows as colored vectors the trajectories of $36 \mathrm{WOCE}$ floats deployed between November 1996 and January 1997 and 8 similar NOAA floats deployed in 1994 and 1995. These floats map out some expected and unexpected aspects of the circulation and should be compared with the schematic shown in Fig. 1. They show the Greenland Current as a strong boundary current off the 
Greenland coast; sustained flows up to $25 \mathrm{~cm} \mathrm{~s}^{-1}$ are observed off the southwest coast. This flow generally follows the bathymetry across the northern Labrador Sea, forming the intermediate depth portion of the southwestward flowing Labrador Current that eventually makes its way past the Grand Banks of Newfoundland. These boundary currents surround the central Labrador Sea, where organized flows are weak compared to the substantial synoptic-scale variability. In most places there is no apparent pattern.

A signature of convection in the Labrador Sea is the mixing of relatively fresh surface waters to increasing depth as surface fluxes extract buoyancy from the upper-water column. Figure 19 shows a time series of potential temperature and salinity profiles from a float deployed near $60.5^{\circ} \mathrm{N}, 57^{\circ} \mathrm{W}$ that moved southeastward roughly paralleling isobaths (it is marked purple in Fig. 18). As time progresses, cool upper-layer temperatures erode the thermocline temperature maximum until it disappears; simultaneously, freshwater is mixed to progressively greater depths. This sequence suggests convection reached about $1200 \mathrm{~m}$ by the end of March. Unfortunately, temporal and spatial variability within the water column make it difficult to determine precisely how deep the convective stirring reached.

In late January 1997, 31 profiling vertical current meter (VCM) floats were deployed in the CFD area marked in Fig. 9 where deep convection was expected to be most vigorous. Individual displacements from 16 of these floats are shown as black vectors in Fig. 18. These instruments recorded vigorous vertical velocities associated with convection. Figure 20 shows a set of three temperature profiles describing a mixed layer that deepens by about $100 \mathrm{~m}$ over 10 days. The figure also shows vertical velocity time series from the two intervals between these profiles. Vertical flows of $5 \mathrm{~cm} \mathrm{~s}^{-1}$ are frequent and there is one example of a plume with peak velocities of $10 \mathrm{~cm} \mathrm{~s}^{-1}$ and a duration of $6-8 \mathrm{~h}$. The general magnitude of vertical velocity is comparable to that observed by Schott et al. (1996) from moored acoustic Doppler current profilers (ADCPs) during convective events in the northern Mediterranean. The event duration is much longer than was seen in the moored results, consistent with the idea that plumes with widths of order $500 \mathrm{~m}$ were advected past the moorings while the VCM approximately follows the plume's horizontal motion.

\section{(ii) Three-dimensional Lagrangian floats}

The three-dimensional trajectories of water parcels in deep convection were measured using a new type of subsurface float, the "deep Lagrangian float". These combine high drag, a compressibility that is very close to that of seawater, and nearly neutral buoyancy to closely match the physical properties of seawater and thus follow its motion in three dimensions. They are tracked acoustically (RAFOS) ${ }^{2}$ in the horizontal and by pressure in the vertical and measure the temperature of the water with submillidegree resolution. A total of 13 deep Lagrangian floats were deployed in the Labrador Sea in February 1997 in the CFD area; 10 more will be deployed in January 1998.

Figure 21 shows some preliminary data. The float is deployed, sinks to $1000 \mathrm{~m}$ below the layer of active convection, and begins a 7-day autoballasting sequence. It then lightens itself slightly and rises into

${ }^{2}$ RAFOS (not an acronym) is a float that receives sound signals.
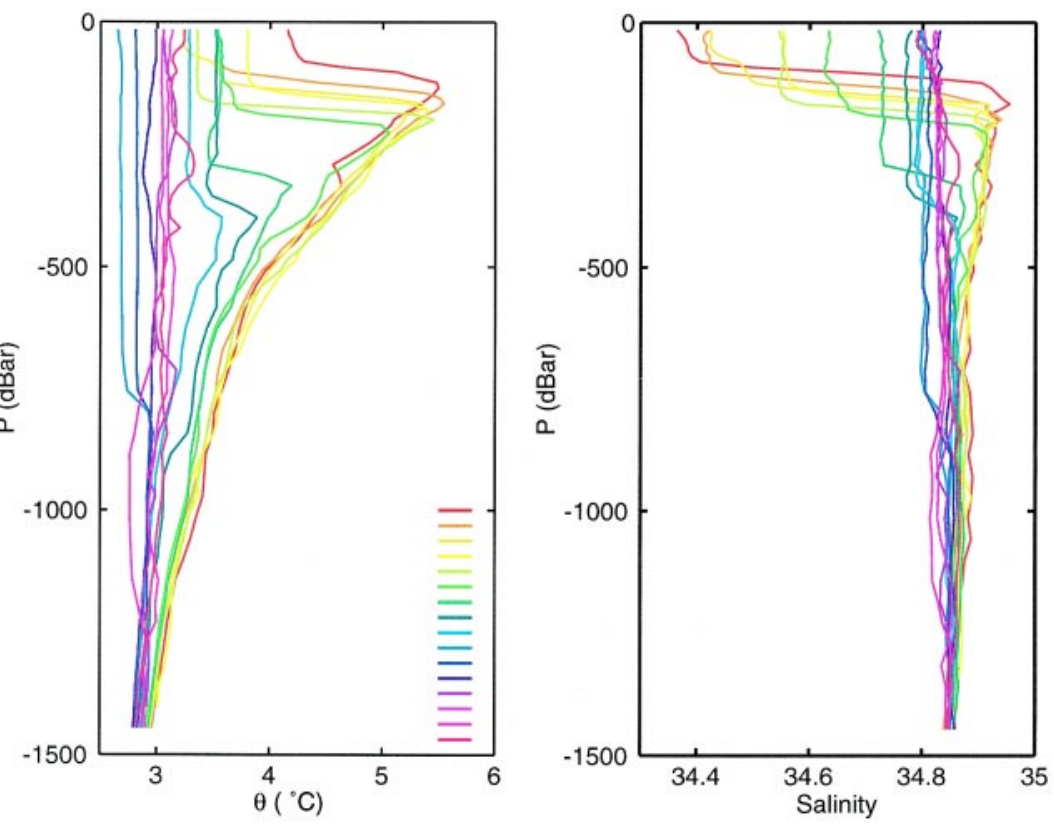

FIG. 19. Time sequence of potential temperature and salinity profiles from a profiling float. There is a profile every 10 days from 2 December 1996 to 25 April 1997 following the color sequence in the temperature plot from top to bottom. The strong salinity-stabilized temperature inversions are typical. It appears that convection had reached $1200 \mathrm{~m}$ by late March (courtesy of R. Davis). 

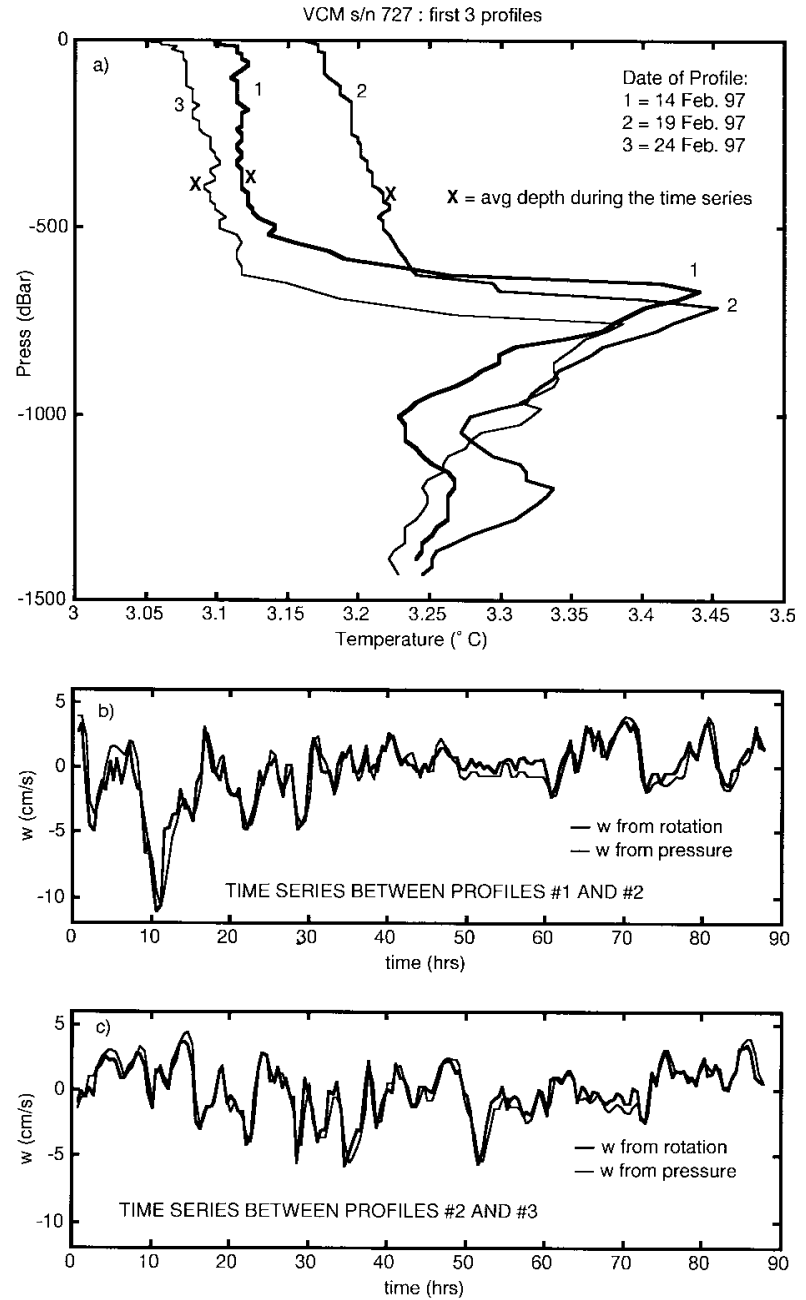

FIG. 20. Upper panel shows a sequence of three temperature profiles at 5-day intervals from a VCM float. Lower panels are 4-day time series of vertical velocity from the intervals between the profiles taken near 380-m depth. Thick lines indicate directly measured velocities and thin lines are a confirming measurement from a simple model balancing vertical drag and float buoyancy. Deepening of the quasi-mixed surface layer and vigorous vertical motion indicate this was a period of active convection (courtesy of R. Davis).

the convecting layer. For the next 25 days, the floats cycle between the surface and $500-800 \mathrm{~m}$, with vertical velocities often exceeding $10 \mathrm{~cm} \mathrm{~s}^{-1}$. Two excursions to $1000 \mathrm{~m}$ can be seen. The rms vertical velocity, $2.3 \mathrm{~cm} \mathrm{~s}^{-1}$, is approximately that expected for convection with a surface heat flux of $400 \mathrm{~W} \mathrm{~m}^{-2}$. The water is cooler when going down than when coming up, as expected for convection. Overall, the data indicate the presence of a nearly continuously convecting layer, deepening with time.

\section{(iii) RAFOS floats}

A total of 33 RAFOS floats were deployed from October 1996 to May 1997 from three cruises of the CSS Hudson (twice) and the R/V Knorr (see Fig. 9). The nominal pressure surfaces were set to one of the following: 150, 350, or $600 \mathrm{dbars}$. The mission lengths extended from 1 to 10 months. The early floats clearly demonstrated the cooling of the surface mixed layer during October and November (Fig. 22) and imply a surface heat flux estimate of $160 \mathrm{~W} \mathrm{~m}^{-2}$. Floats deployed later measured the effects of convective events, particularly strong downward velocities, and the associated turbulent heat fluxes. In addition, floats have been deployed off Greenland to capture the eddydriven transport of Irminger water into the Labrador Sea, and the resulting capping and advective-driven restratification of the basin interior. As more data become available, we anticipate mapping the spatial and temporal distributions of convective activity in the context of the geostrophic eddy and basin circulation fields.

\section{3) MoORINGS AND TOMOGRAPHY}

In May 1994 a long-term site mooring was established at $56.75^{\circ} \mathrm{N}, 52.5^{\circ} \mathrm{W}$ near the location of former weather station Bravo (Lilly et al. 1998). The mooring, together with the repeated hydrographic sampling on CSS Hudson, had provided an extended record of wintertime convection as a lead-in to and motivation for the intensive experiment during 1996-98. It has 15 instruments and measures temperature, salinity, three-component velocity, as well as passive noise. The velocity field revealed by the mooring involves strong synoptic-scale and mesoscale eddies with nearly barotropic vertical structure, in which are embedded finescale convective plumes. Both scales of eddy are energized at the time of deep convection.

An array of moorings was deployed along the AR7 hydrographic line over the winter of 1996-97 (see Table 1 and Fig. 9). It was designed to measure horizontal currents by rotor current meters and ADCPs to record variability in convection by temperature and conductivity measurements, as well as vertical currents from ADCPs and to determine the integral effects of deep convection by acoustic tomography.

The Bravo mooring gives an Eulerian picture of the deep convection process, sampling a 100-km diameter region of ocean as eddies sweep fluid past it. It thus complements the wider range of scales sampled by the drifting floats. The potential temperature field for October 1996-May 1997 (Fig. 23) shows the build up 


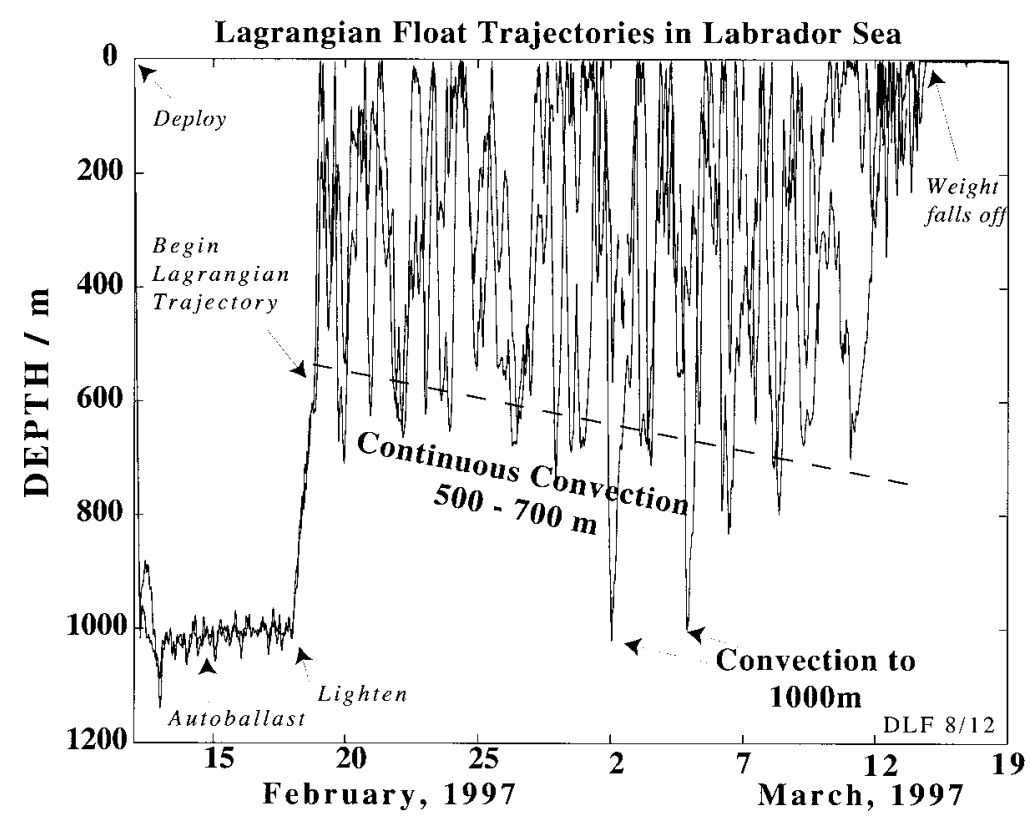

FIG. 21. Data from Lagrangian floats deployed in the Labrador Sea over a period of $\sim 1$ month starting in mid-February 1997. Continuous convection to $800 \mathrm{~m}$ with deeper convection to $1000 \mathrm{~m}$ is evident (courtesy of E. d'Asaro). geneity of the convection, though the scale of that inhomogeneity is not yet certain.

Vertical velocities were also recorded on other moorings. For example, the K1 ADCP (see Fig. 9) over the depth range $440-700 \mathrm{~m}$ shows plumes of $3-6 \mathrm{~cm} \mathrm{~s}^{-1}$ during 12-22 February and again during 3-9 March. While during the first period, significant temperature fluctuations in the water column remained above the ADCP, homogeneity was fairly complete during the second period. During the Meteor cruise in summer 1997, the array was redeployed, this time moving the tomography transceiver from $\mathrm{K} 3$ to $\mathrm{K} 2$, in order to concentrate on the area that had shown the most convective activity during the 1996-97 winter Knorr cruise. Some of the lines covered with tomography were also designed to coincide with the inverted echo sounder sections, with the hope of combining transport estimated from the latter with tomography heat content. of warm, saline, buoyant fluid about January, when convective deepening arrives at the top instrument (96$m$ depth). The buoyancy barrier of the upper few hundred meters is slowly eroded, and as the air-sea heat flux intensifies, the weaker deep stratification is rapidly broken through. The weak winter of 1995-96 left a large amount of heat and freshwater in the upper ocean, but the much stronger winter cooling of 1996-97 was able to reach great depth. Convection reached $1500 \mathrm{~m}$ in waters passing the mooring, though the average depth of the mixed layer is closer to $1000 \mathrm{~m}$.

The water column at the mooring was homogeneous down to $1000 \mathrm{~m}$ for only about two weeks in late March 1997 , suggesting that convection is indeed inhomogeneous. Direct measurement of convective plumes by the ADCP showed vertical velocities exceeding $10 \mathrm{~cm} \mathrm{~s}^{-1}$. The short duration of the strong downwelling $(\sim 2-4 \mathrm{~h})$ suggests that the width of the features advecting past is between 200 and $800 \mathrm{~m}$. Restratification of the water column occurs deeply and quickly after winter, the freshwater invading near the surface and saline, warm water at all depths below; it reflects the inhomoPrater).

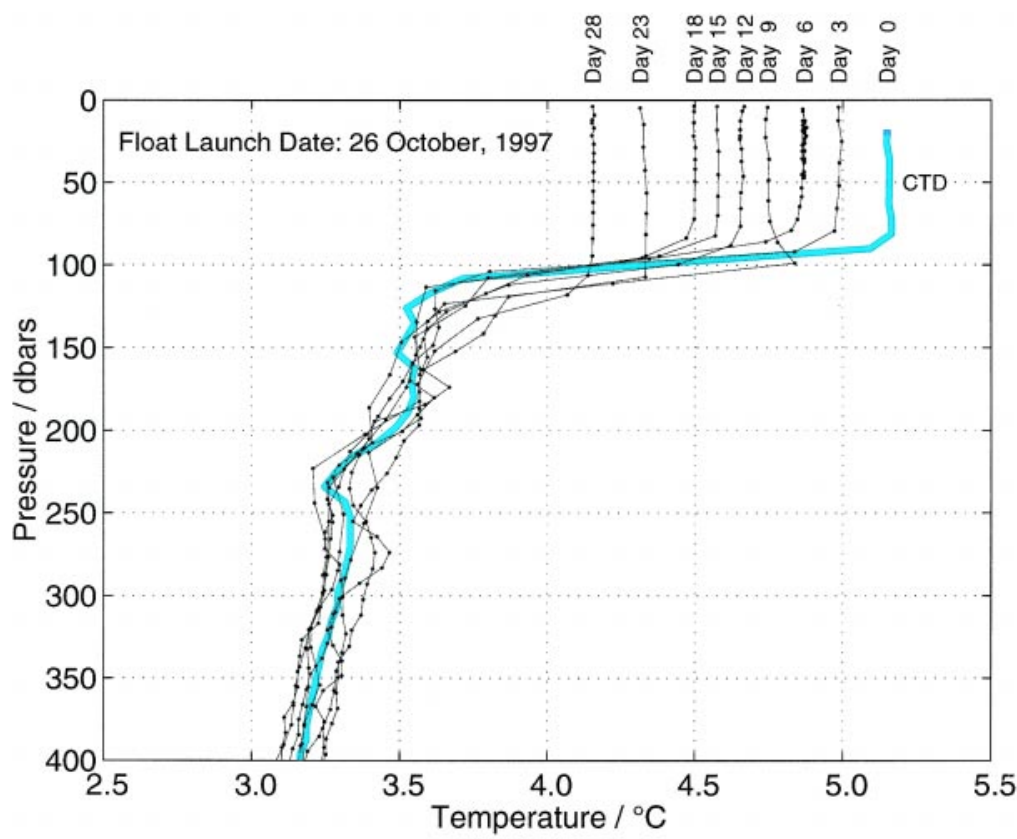

FIG. 22. Temperature profiles as measured by a RAFOS float. The first six profiles were made at 3-day intervals, the last two profiles were at 5-day intervals. The dots are individual temperature-pressure measurements while the thick line is from a CTD cast taken 3 days prior to the first profile. The steady cooling and gradual deepening of the mixed layer can be clearly seen (courtesy of $\mathrm{M}$. 


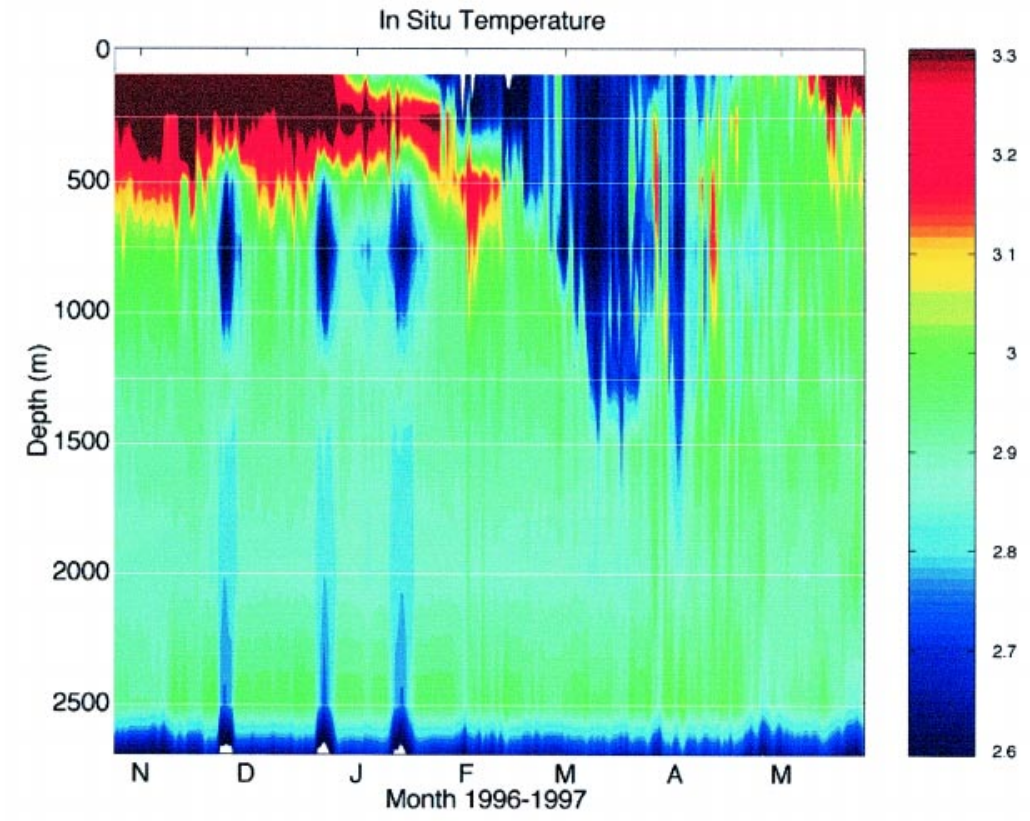

FIG. 23. The potential temperature $\left({ }^{\circ} \mathrm{C}\right)$ field for October 1996-May 1997 at the Bravo mooring (see Fig. 9) showing the build up of warm (and saline) buoyant fluid until January, the subsequent deepening in excess of $1500 \mathrm{~m}$, and then restratification in May (courtesy of P. Rhines).

\section{Summary and future plans}

The dataset that has been gathered in the Labrador Sea far exceeds previous efforts to observe the convective process anywhere in the World Ocean, both in the scope and range of techniques employed and because of the presence of the contemporaneous meteorological component. It is giving us unprecedented insights into the meteorology and oceanography of the Labrador Sea, a region known to have direct influence on the processes that control global climate. The meteorology and oceanography are interesting in their own right, but perhaps the most exciting aspect of the experiment is the glimpse it is giving us of the interplay and interaction between the two fluids.

Our experiment was the first in which direct measurements of the fluxes of heat, momentum, and moisture were taken across the air-sea interface in the Labrador Sea. Preliminary results suggest that modelderived estimates of these fluxes are significantly higher than our direct measurements.

The pronounced observed spatial pattern in the precipitation (virtually none near the ice edge and increasing with downwind distance from the edge) is equivalent to salt being injected in to the ocean near the edge and removed downwind. How important is this pattern of salinity flux on deep ocean convec- tion? Based on atmospheric data from the ship and typical upper-ocean conditions, we found that the direct effect of heat fluxes on the ocean buoyancy was about five times the salinity effects of evaporation. Precipitation had a similar but opposite (stabilizing) effect. Both the pattern of heat fluxes (maximum near the ice edge) and the salinity fluxes (maximum evaporation near ice edge, maximum precipitation downwind of ice edge) would concentrate the destabilizing forcing of the ocean on the upwind (here the western) side of the Labrador Sea, as indicated schematically in Fig. 10. In addition, a potentially important mechanism in the overall surface buoyancy in the area, but one that we are unable to quantify or model, must be surface meltwater from the Labrador ice pack. We observed ice close to the pack melting rapidly in the $3-4^{\circ} \mathrm{C}$ sea surface temperatures.

Much is being revealed about the response of the ocean by our combination of Eulerian and Lagrangian measurements. Many questions are being raised by the data. Are the geostrophic scales as important in the vertical transfer of heat-balancing a significant fraction of its loss from the surface-as initial estimates from float data suggest? How do the observed vertical velocity and temperature fluctuations vary in space and time? Existing models of dynamics on the plume scale predict how such properties are related to surface forcing and the general stratification. A knowledge of these fields over the observational area will allow both qualitative and quantitative tests of these theories. Do theories explain the origin of the observed intrusive T/S variability? This would seem a critical indicator of the process by which convective stirring eventually leads to mixing. Do theories predict the substantial difference in the timescale of vertical velocity and temperature fluctuations? Since floats are neither Eulerian nor truly Lagrangian, this will likely require tracking model floats through the density and velocity fields of plume-scale dynamical models, as in Harcourt et al. (1997), in order to generate time series that can be compared to those observed.

The experiment has profound implications for the representation of convection in large-scale models. Parameterizations of convection widely used in largescale ocean models remain stubbornly one-dimen- 
sional and bear little relation to the phenomenology we are observing in the field and in our process models of convection (both laboratory and numerical). The detailed description of the water mass transformation process that is emerging emphasizes the pervasiveness of the quasi-horizontal stirring processes that preexist in the ocean and are rapidly energized as convection proceeds. These lateral stirring processes may be the ones that ultimately lead to mixing.

The second phase of the field experiment, during January 1998, repeated a subset of the observations described here and observed the mixed layer deepening down to $600 \mathrm{~m}$ or so. Moreover, new technology in the form of self-propelled autonomous underwater vehicles carried out fine-resolution surveys of the convecting mixed layer akin to atmospheric boundary layer aircraft flights. These, together with more conventional observations, may give us a clearer view of the structure of the convective elements themselves.

Acknowledgments. The LSCE was supported by ONR, NOAA, and NSF in the United States, by DFG and BMBF in Germany, and by DFO and the Panel for Energy R\&D in Canada. Access to the NCEP-NCAR Reanalysis products was provided by the Climate Diagnostics Center of NOAA. ECMWF also made available their analysis products to us and helped us ensure that our in situ measurements got onto the GTS. We should like to acknowledge, in particular, the unstinting support of Dr. Manuel Fiadeiro of ONR, whose interest and enthusiasm for this project made it possible.

\section{References}

Clarke, R. A., and J.-C. Gascard, 1983: The formation of Labrador Sea water. Part 1: Large-scale processes. J. Phys. Oceanogr., 13, 1764-1788.

Dickson, R., J. Lazier, J. Meinke, P. Rhines, and J. Swift, 1996: Long-term coordinated changes in convective activity of the North Atlantic. Progress in Oceanography, Vol. 38, Pergamon Press, 241-295.

Fischer, K. W., S. Legg, W. H. Munk, R. A. Shuchman, R. W. Garwood, and J. P. Palshook, 1998: Modeled Radar Surface Signature of Deep Ocean Convection. IEEE Trans. Geosci. Remote Sens., in press.

Garwood, R. W., Jr., 1991: Enhancements to deep turbulent entrainment. Deep Convection and Deep Water Formation in the Oceans, P. C. Chu and J. C. Gascard, Eds., Elsevier Science, 197-213.

_ S. Isakari, and P. Gallacher, 1994: Thermobaric convection. The Polar Oceans and Their Role in Shaping the Global Environment, Geophys. Monogr., No. 85, Amer. Geophys. Union, 199-209.

Harcourt, R., L. Jiang, and R. Garwood, 1997: Numerical simulation of drifter response to Labrador Sea convection. ONR Naval Postgraduate Rep., 110 pp.
Hodur, R. M., 1997: The Naval Research Laboratory's Coupled Ocean-Atmosphere Mesoscale Prediction System (COAMPS). Mon. Wea. Rev., 125, 1414-1430.

Hurrell, J. W., 1995: Decadal trends in the North Atlantic oscillation regional temperatures and precipitation. Science, 269, 676-679.

Joly, A., and Coauthors, 1997: The Fronts and Atlantic Storm Track Experiment (FASTEX): Scientific objectives and experimental design. Bull. Amer. Meteor. Soc., 78, 19171940.

Jones, H., and J. Marshall, 1993: Convection with rotation in a neutral ocean: A study of open-ocean deep convection. J. Phys. Oceanogr., 23, 1009-1039.

Julien, K., S. Legg, J. McWilliams, and J. Werne, 1996: Penetrative convection in rapidly rotating flows: Preliminary results from numerical simulation. Dyn. Atmos. Oceans, 24, 237249.

Kalnay, E., and Coauthors, 1996: The NCEP/NCAR 40-Year Reanalysis Project. Bull. Amer. Meteor. Soc., 77, 437-471.

Legg, S., and J. Marshall, 1993: A heton model of the spreading phase of open-ocean deep convection. J. Phys. Oceanogr., 23, 1040-1056.

__ J. McWilliams, and J. Gao, 1998: Localization of deep ocean convection by a mesoscale eddy. J. Phys. Oceanogr., 28, 944970.

Levitus, S., J. I. Antonov, and T. P. Boyer, 1994: Interannual variability of temperature at a depth of 125 meters in the North Atlantic Ocean. Science, 266, 96-99.

Lilly, J., P. B. Rhines, M. Visbeck, R. Davis, J. R. N. Lazier, F. Schott, and D. Farmer, 1998: Observing deep convection in the Labrador Sea during winter 1994-95. J. Phys. Oceanogr., in press.

Marshall, J., and F. Schott, 1998: Open ocean deep convection: Observations, theory and models. Rev. Geophys., in press.

— C. Hill, L. Perelman, and A. Adcroft, 1997: Hydrostatic, quasi-hydrostatic, and nonhydrostatic ocean modeling. $J$. Geophys. Res., 102 (C3), 5733-5752.

Maxworthy, T., and S. Narimousa, 1994: Unsteady, turbulent. convection into a homogeneous, rotating fluid, with oceanographic applications. J. Phys. Oceanogr., 24, 865-887.

MEDOC Group, 1969: Observations of deep-water formation in the northwestern Mediterranean Sea. Nature, 227, 10371040.

Pickart, R. S., and W. M. Smethie Jr., 1998: Temporal evolution of the Deep Western Boundary Current where it enters the subtropical domain. Deep-Sea Res., in press.

Renfrew, I. A., G. W. K. Moore, T. Holt, and S. Chang, 1998: Mesoscale forecasting during a field program: Meteorological support of the Labrador Sea Deep Convection Experiment. Bull. Amer. Meteor. Soc., in press.

Reverdin, G., D. Cayan, and Y. Kushnir, 1997: Decadal variability of hydrography in the upper North Atlantic 1948-1990. J. Geophys. Res., 102, 8505-8531.

Rogers, J. C., 1990: Patterns of low-frequency monthly sea level pressure variability (1899-1986) and associated wave cyclone frequencies. J. Climate, 3, 1364-1379.

Schott, F., M. Visbeck, U. Send, J. Fischer, L. Stramma, and Y. Desaubies, 1996: Observations of deep convection in the Gulf of Lions, northern Mediterranean, during the winter of 1991/92. J. Phys. Oceanogr., 26, 505-524. 
Send, U., F. Schott, F. Gaillard, and Y. Desaubies, 1995: Observation of a deep convection regime with acoustic tomography. J. Geophys. Res., 100 (C4), 6927-6941.

Smith, S. D., 1988: Coefficients for sea surface wind stress, heat flux and wind profiles as a function of wind speed and temperature. J. Geophys. Res., 93 (C12), 15 467-15 472.

van Loon, H., and J. C. Rogers, 1978: The seesaw in winter temperatures between Greenland and Northern Europe. Part 1. Mon. Wea. Rev., 106, 296-310.
Vautard, R., 1990: Multiple weather regimes over the North Atlantic: Analysis of precursors and successors. Mon. Wea. Rev., 118, 2056-2081.

Visbeck, M., J. Marshall, and H. Jones, 1996: Dynamics of isolated convective regions in the ocean. J. Phys. Oceanogr., 26, 1721-1734.

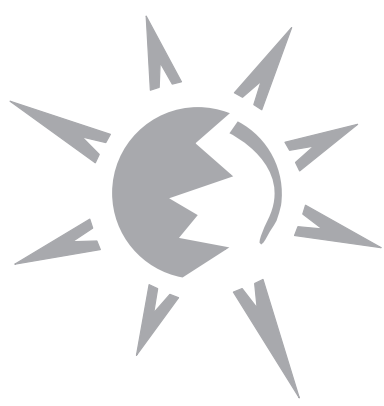

